\title{
Digital twin-based sustainable intelligent manufacturing: a review
}

\author{
Bin $\mathrm{He}^{1}{ }^{1} \cdot$ Kai-Jian $\mathrm{Bai}^{1}$
}

Received: 29 June 2019/Revised: 4 September 2019/Accepted: 26 March 2020/Published online: 4 May 2020

(C) The Author(s) 2020

\begin{abstract}
As the next-generation manufacturing system, intelligent manufacturing enables better quality, higher productivity, lower cost, and increased manufacturing flexibility. The concept of sustainability is receiving increasing attention, and sustainable manufacturing is evolving. The digital twin is an emerging technology used in intelligent manufacturing that can grasp the state of intelligent manufacturing systems in real-time and predict system failures. Sustainable intelligent manufacturing based on a digital twin has advantages in practical applications. To fully understand the intelligent manufacturing that provides the digital twin, this study reviews both technologies and discusses the sustainability of intelligent manufacturing. Firstly, the relevant content of intelligent manufacturing, including intelligent manufacturing equipment, systems, and services, is analyzed. In addition, the sustainability of intelligent manufacturing is discussed. Subsequently, a digital twin and its application are introduced along with the development of intelligent manufacturing based on the digital twin technology. Finally, combined with the current status, the future development direction of intelligent manufacturing is presented.
\end{abstract}

Keywords Intelligent manufacturing - Digital twin . Advanced manufacturing · Industry $4.0 \cdot$ Sustainable manufacturing

Bin $\mathrm{He}$

mehebin@gmail.com

1 Shanghai Key Laboratory of Intelligent Manufacturing and Robotics, School of Mechatronic Engineering and Automation, Shanghai University, Shanghai 200444, People's Republic of China

\section{Introduction}

As an upgrade to manufacturing industries, Industry 4.0 proposed next-generation intelligent manufacturing to achieve high adaptability, rapid design changes, digital information technology, and more flexible technical workforce training. Manufacturing technologies include cyber-physical systems [1, 2], Internet of Things (IoT) [3], and cloud computing $[4,5]$. In the Industry 4.0 era, intelligent manufacturing has received increasing attention owing to the need for sustainability. Intelligent manufacturing should consider sustainability aspects [6], and intelligent manufacturing equipment, such as computerized numerical control (CNC) machine tools and industrial robots [7-10], should have more intelligence, which aid their better integration into the intelligent manufacturing closed loop to complete manufacturing tasks. Intelligent manufacturing systems are showing a diversified trend, and an increasing number of them are being developed for specific tasks and applied to actual production, thereby greatly improving the level of intelligence [11-16]. New services for intelligent manufacturing are explored and improved, and the sustainable collaborative manufacturing system platform integrates customers, experts, and enterprises and provides them with personalized services [17-24].

A complete real-time presentation of the state of the intelligent manufacturing system is a challenge; however, the emergence of a digital twin has made it possible to solve this problem [25-27]. Manufacturing systems can monitor physical processes, create a digital twin in the physical world [28], receive real-time information from the physical world for simulation analysis, and make informed decisions through real-time communication and collaboration with humans. The combination of digital twin and 
intelligent manufacturing makes manufacturing smarter, more efficient, and more convenient.

This paper is devoted to reviewing digital twin-driven sustainable intelligent manufacturing, which summarizes the intelligent manufacturing that uses a digital twin from a sustainable perspective. Firstly, the concept and application of a digital twin are introduced along with the application of the digital twin from three aspects: product design, manufacturing, and product service. Secondly, digital twindriven sustainable intelligent manufacturing is introduced from three aspects: intelligent manufacturing equipment, system, and service (see Fig. 1).

Sustainable intelligent manufacturing contains sustainable intelligent manufacturing equipment, system, and service, which support each other. Intelligent manufacturing equipment is introduced from two dimensions: intelligent manufacturing unit and line. From the perspective of a life cycle, the intelligent manufacturing system is divided into four parts: design, production, logistics and sales. Intelligent manufacturing services are introduced from three aspects: product development, manufacturing, and after-sales services. Finally, the development trend of intelligent manufacturing is summarized from three aspects: framework, enabling technology and application of sustainable intelligent manufacturing. The framework of sustainable intelligent manufacturing includes sustainable intelligent design, comprehensive sustainability, humanmachine collaboration, sustainable intelligent manufacturing for product life cycle, across enterprise value chain, for product environmental footprint, and sustainable intelligent manufacturing equipment, system, and service. The enabling technology of sustainable intelligent manufacturing includes digital twin-based big data-driven, artificial intelligence-driven, and Internet of Things (IoTs)-driven sustainable intelligent manufacturing.

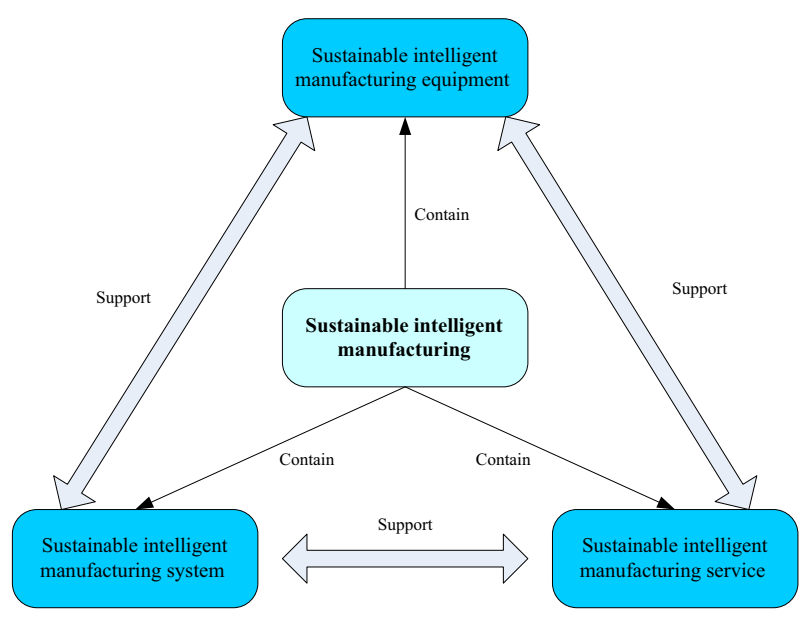

Fig. 1 Three aspects of intelligent manufacturing

\section{Digital twin}

\subsection{Concept of digital twin}

The idea of a digital twin was described as an information mirror model by Grieves [29]. A digital twin is a digital replica of a living or non-living physical entity. It enables a seamless transfer of data by connecting physical and virtual worlds [30], thereby allowing virtual entities to exist simultaneously with physical entities. The definition of the digital twin technology emphasizes two important features. Firstly, each definition emphasizes the connection between the physical model and the corresponding virtual model or virtual counterpart. Secondly, the connection is established by using sensors to generate real-time data [31, 32]. Table 1 lists some definitions of a digital twin in Refs. [30, 31-37].

Based on the definitions provided in the abovementioned literature, a digital twin is a real-time digital reproduction of physical entities. It faithfully maps physical objects and can not only describe physical objects, but also optimize physical objects based on models.

\subsection{Applications of digital twin}

The digital twin technology has recently received widespread attention. The world's most authoritative IT research and advisory firm, Gartner, chose digital twin as one of the top ten strategic technology trends since 2016. Lockheed Martin, the world's largest weapon manufacturer, listed digital twin as the first of six top technologies in the defense and aerospace industry in 2017. The China Association for Science and Intelligent Manufacturing academic consortium also selected digital twin intelligent manufacturing assembly as one of the top 10 scientific and technological progresses in intelligent manufacturing in 2017. A digital twin chooses products as the main research object. Digital twin technology exists in different stages of the product life cycle, and different elements are introduced at each stage. Therefore, digital twin has different performance forms. This section introduces the digital twin application from three aspects: product design, manufacturing and product service.

\subsubsection{Digital twin in product design}

The digital twin application in product design is mainly based on digital twin research product design methods to make it more efficient. This includes digital design and digital simulation. 
Table 1 Definition of digital twin in the literature

\begin{tabular}{lc}
\hline Definition & Refs. \\
\hline $\begin{array}{l}\text { Digital twin is an integrated multi-physics, multi-scale, probabilistic simulation of completed vehicles } \\
\text { or systems that use the best physical models, sensor updates, fleet history, etc. to reflect the life of }\end{array}$ & $\begin{array}{c}\text { Glaessgen and } \\
\text { their corresponding flying twin }\end{array}$ \\
$\begin{array}{l}\text { Digital twin is digital copies of biological or non-biological physical entities. By bridging the physical } \\
\text { and virtual worlds, data is seamlessly transferred, allowing virtual entities to exist simultaneously }\end{array}$ & Abdulmotaleb [30] \\
with physical entities & Lee et al. [34] \\
A coupled model of real machines running on a cloud platform that uses a combination of data-driven & Söderberg et al. [35] \\
analysis algorithms and other available physics knowledge to simulate health conditions & Bolton et al. [36] \\
Real-time optimization using digital copies of physical systems & Tao et al. [37] \\
$\begin{array}{l}\text { The dynamic virtual representation of a physical object or system throughout its lifecycle, using real- } \\
\text { time data to achieve understanding, learning, and reasoning }\end{array}$ & \\
$\begin{array}{l}\text { Digital twin uses physical data, virtual data and interactive data between them to map all components } \\
\text { in the product lifecycle }\end{array}$ & \\
\hline
\end{tabular}

\subsubsection{Digital design Modeling tools are used to build} virtual models of the products to visually express their physical parameters. A product design method based on a digital twin was proposed, and the framework of the digital twin product design was analyzed [37]. A new cloud-based digital twin approach was developed for network physics cloud manufacturing platforms to reduce computing resources and enable an efficient interaction between users and physical machines [38]. Product design, manufacturing, and service approach were proposed, driven by a digital twin to make the product design, manufacturing, and service more efficient [39]. Schleich et al. [40] proposed a comprehensive reference model based on the concept of skin model shape, which corresponded to physical products in design and manufacturing. The digital twin-driven product design method enables researchers to quickly find design flaws and improve design efficiency when designing products.

2.2.1.2 Digital simulation The adaptability could be verified at the design stage through a series of simulation experiments to verify the product performance. Haag and Anderl [41] developed a network physical bending beam test rig to demonstrate the digital twin concept. A modular approach was studied to build a digital twin and make the corresponding changes [42]. Using the built-in flexible digital twin helps designers quickly evaluate different designs and find design flaws. A method was proposed for modeling and operating a digital twin in a manufacturing environment [43]. At the design stage, researchers use simulation experiments to verify the product, which greatly improves the product adaptability.

\subsubsection{Digital twin in manufacturing}

The digital twin application in manufacturing is mainly based on the virtual simulation model of a digital twin to build a solid model, which is applied to the product processing and assembly to achieve precise production control. This part includes the production process simulation, digital production line, and equipment status monitoring.

\subsubsection{Production process simulation Before product} production, the production process can be simulated by means of virtual production, and productivity and efficiency can be comprehensively analyzed. A new method was proposed for resource supply and demand matching manufacturing based on complex networks and IoTs to realize the intellectual perception and access to manufacturing resources [44]. Bilberg and Malik [45] applied a digital twin to the assembly unit to create a digital twin model that extended the use of virtual simulation models developed during the production system design phase to implementation control, human and machine task assignment, and task sequencing. Um et al. [46] proposed a universal data model based on a digital twin to support plug-and-play in modular, multi-vendor assembly lines. A digital twin with intelligent manufacturing services was combined to produce more sensible manufacturing planning and precise production control [47]. A digital network-based manufacturing network physics system was proposed to control intelligent workshops in parallel under a large-scale personalization paradigm [48]. A factory network physical integration framework was proposed for digital-based systems to address the problems faced by digital factories and shift the current state of digital factories to intelligent manufacturing [49].

2.2.2.2 Digital production line All the elements of the production stage are integrated into a closely coordinated production process through digital methods to achieve an automated production process. The digital twin model was studied using the digital twin technology to control robots to automatically assemble large spacecraft components 
[50]. Digital twin modeling and data fusion issues at each steel product life cycle stage were explored to achieve complex tasks [51]. A digital twin-based approach was studied for the rapid personalization of insulated glass production lines [52]. Moreover, a framework was proposed for intelligent production management and control methods using the digital twin technology and applied to assembly shops for complex products [53]. A digital twin method was proposed for the rapid personalization of automated flow shop manufacturing systems, combining physical system modeling and semi-physical simulation to generate authoritative digital designs of the system during the pre-production phase [54]. Liau et al. [55] applied a digital twin to the injection molding industry, modeling all stages of injection molding as virtual models to achieve a two-way control of physical processes.

\subsubsection{Equipment status monitoring The production} process can be monitored visually by collecting the realtime operation data of production equipment. The abnormal equipment must be dealt with and adjusted in time to optimize the production process. Botkina et al. [56] introduced digital twin data formats and structures for cutting tools, information flow, and data management and applied that digital twin to improve machining solutions optimized for process planning. When the digital twin application is applied in the production workshop, the state of the machines and products in the workshop is reflected in the virtual model in real-time, thereby making the manufacture of the product more intelligent.

\subsubsection{Digital twin in product service}

The digital twin application in fault prediction is based on the virtual simulation model of a digital model based on a digital twin. The virtual simulation model faithfully reflects the state of the solid model. The virtual simulation model will generate faults when the solid model fails. This is the fault detection. The virtual simulation model judges whether the physical model will generate a fault based on the real-time state data and can effectively reduce the failure rate. This part includes product fault warning and maintenance and production index optimization.

\subsubsection{Product fault warning and maintenance By} reading the real-time parameters of the sensors or control systems of intelligent industrial products, a visual remote monitoring model is built to analyze the state of products with artificial intelligence and make early warning in time. Meanwhile, maintenance strategies are given to reduce losses. Fault detection and health management can be implemented for different devices based on digital generation. The operation mode of the device can be optimized according to the state data of the virtual model to reduce failure rate and improve stability.

The application of product services aims to combine a digital twin with other technologies, such as virtual reality, to form a new model of digital twin-based services. In the manufacturing sector, Pairet et al. [57] introduced the Offshore Robotics for the Certification of Assets or ORCA Hub simulator for training and testing human-machine collaboration solutions that unify three types of homemade systems on the marine digital twin platform. Voinov et al. [58] studied a method for providing reliable management of complex IoT systems. Uhlemann et al. [59] studied the concept of a learning factory based on the advantages of real-time data acquisition and subsequent simulation data processing. Meanwhile, Coronado et al. [60] developed and implemented a low-cost manufacturing execution system (MES) and an android operating system (OS) application to generate a shop floor digital twin model by collecting machine data enabled by MES and MTConnect. Schluse et al. [61] introduced an experimental digital twin to create interactions in different application scenarios and provided a new foundation for simulation-based integrated systems engineering. Macchi et al. [62] explored the role of a digital twin in asset lifecycle management. Kunath and Winkler [63] discussed the conceptual framework and potential applications of digital twin decision support systems that were eager to manufacture systems in the order management process. Biesinger et al. [64] introduced the digital twin of the body-in-white production system to achieve a rapid integration of new cars. Vachálek et al. [65] introduced a digital twin and supported existing production structures and the most efficient use of resources in the automotive industry through digital production and enhanced production and planning strategies. Uhlemann et al. [66] also introduced multimodal data acquisition methods to ensure the most accurate synchronization of digitally generated network physical processes with real physical models. Tao and Zhang [67] studied the digital twin workshop based on a digital twin and its operation mechanism and implementation method. In the manufacturing process, the carbon emission problem in the manufacturing process should also be considered in addition to ensuring the manufacturing stability [68].

The progress made by the digital twin technology in the research of medical, sports, manufacturing, etc., has led to the continuous development of these industries. In the medical field, Martinez et al. [69] studied the impact of digital twin on service business model innovation by fully understanding how to set up, implement, and use digital health and understanding the impact of digital health in the enterprise services business. A cloud healthcare system 
framework was proposed for digital twin healthcare aimed at achieving the goal of personal health management by integrating medical physics and virtual space [70]. In the field of sports, Balachandar and Chinnaiyan [71] used a digital twin in the field of sports to make virtual connections and monitor athletes in the lab.

\subsubsection{Production index optimization By reading and} analyzing the status data of products, the configuration parameters of products are modified to improve their performance and optimize the production indexes. Guivarch et al. [72] proposed a new method for developing a digital twin for helicopter power systems to better predict the service life of mechanical components. A general digital twin model was established for complex devices. A method was also proposed for using the digital twin to drive prediction and health management to improve the accuracy and efficiency of forecasting and health management [73]. Lynn et al. [74] proposed a network-, physical systembased manufacturing system for implementing process control and optimization. A multi-domain unified modeling method was established for the digital twin to study its computer numerical control (CNC) machine tools and make these tools more intelligent while optimizing the operating mode, reducing the sudden failure rate, and improving the CNC machine tool stability [75]. Dynamic Bayesian networks were used to build multi-function diagnostic and predictive probabilistic models to achieve a digital twin [76].

\section{Digital twin-driven sustainable intelligent manufacturing}

Research on digital twin-driven intelligent manufacturing is a hot trend and has achieved good results in life cycle management, data fusion, rapid production, intelligent forecasting, and sustainable manufacturing [77-85]. Intelligent manufacturing is a deep integration between the artificial intelligence technology and the advanced manufacturing technology. The new generation artificial intelligence technology mainly includes cloud computing, IoTs and big data, among others. Intelligent manufacturing brings great changes to all aspects of the manufacturing industry, making it capable of learning, generating, and using knowledge. The digitalization, networking, and intelligence of intelligent manufacturing have been balanced.

Intelligent manufacturing is a broad manufacturing category that uses computer integrated manufacturing, high levels of adaptability and rapid design changes, digital information technology, and more flexible technical workforce training. Figure 2 shows the system architecture of intelligent manufacturing, which describes the activities,

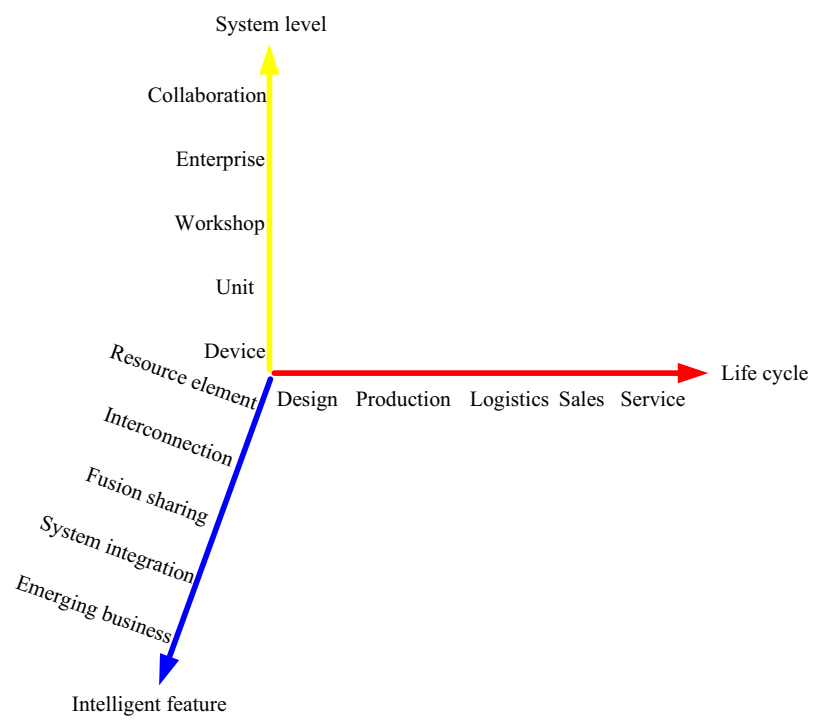

Fig. 2 System architecture of intelligent manufacturing [86]

equipment, features, and others involved in intelligent manufacturing from three dimensions, namely life cycle, system level, and intelligent features [86].

The intelligent manufacturing technology is the deep integration and integration of the information technology, intelligent technology, and equipment manufacturing technology. The intelligent manufacturing technology is based on advanced technologies, such as the modern sensing technology, network technology, automation technology, and anthropomorphic intelligence technology. The intelligent manufacturing technology can realize intelligent design process, intelligent manufacturing process, and intelligent manufacturing equipment through intelligent sensing, human-computer interaction, decision making, and execution technology. In addition, the concept of sustainable $[87,88]$ manufacturing is receiving increasing attention, and intelligent manufacturing should be sustainable [89].

Intelligent manufacturing plays a pivotal role in nextgeneration manufacturing, especially in high-end manufacturing; hence, the world's traditional manufacturing powers and new manufacturing powers have come up with plans to develop intelligent manufacturing. Table 2 presents the intelligent manufacturing development plans of some countries and organizations [90-95]. This section describes intelligent manufacturing in terms of intelligent manufacturing equipment, intelligent manufacturing systems, and intelligent manufacturing services.

\subsection{Sustainable intelligent manufacturing equipment}

Intelligent manufacturing equipment refers to manufacturing equipment with sensing, analysis, reasoning, decision-making, and control functions. It is a deep integration 
Table 2 Main intelligent manufacturing development plans in the world

\begin{tabular}{lll}
\hline Country/organization & Intelligent manufacturing development plan & Refs. \\
\hline Germany & Industry 4.0 & [90] \\
European Union & Horizon 2020 & [91] \\
Japan & Industrial Value Chain Initiative & {$[13]$} \\
United States & Advanced Manufacturing Partnership & [92] \\
South Korea & Manufacturing Industry Innovation 3.0 strategy & [90] \\
United Kingdom & Modern industrial strategy & [93] \\
France & New France Industrial & [94] \\
China & Made in China 2025 & [95] \\
\hline
\end{tabular}

of the advanced manufacturing technology, information technology, and intelligent technology. The development of intelligent manufacturing equipment reflects the level of the manufacturing industry. Intelligent manufacturing equipment can be classified into two types: intelligent manufacturing unit and intelligent manufacturing production line.

\subsubsection{Intelligent manufacturing unit}

The intelligent manufacturing unit is an independent processing equipment in intelligent manufacturing, which is the smallest processing unit for intelligent manufacturing. A knowledge-driven digital twin manufacturing unit that supports self-manufacturing for the overall framework of intelligent manufacturing was proposed [96]. Lohtander et al. [97] studied the digital twin technology based on micro-manufacturing units. The intelligent manufacturing unit contains various processing equipment, such as machine tools, robots, and special equipment.

3.1.1.1 Machine tools and equipment The machine tool is mainly used to perform machining tasks. From the first machine tool to the present, the machine tool has achieved great development. The style, type, and technology also experienced revolutionary innovation.

CNC machine tools are automatic machine tools with a program control system, which could solve the processing problems of complex and precision products and represent the development trend of modern machine tools. Compared with traditional machine tools, $\mathrm{CNC}$ machine tools have the following advantages: high processing precision, stable processing quality, high productivity and flexibility. Many researchers conducted intelligent manufacturing-related research on $\mathrm{CNC}$ machine tools.

A fault diagnosis strategy based on cascade faults was proposed to ensure the safe operation of CNC machine tools [98]. The state-based monitoring architecture was used for the alarm management of CNC machine tools
[99]. Yang et al. [100] proposed a method to accurately determine the critical point of thermal coupling deformation of machine tools. A two-dimensional thermal error compensation method was proposed for the thermal error compensation of CNC machine tools, which greatly improved the compensation effect of the workbench [101]. An improved energy consumption model that effectively reflected the relationship between processing parameters and energy consumption in machining processes was proposed based on empirical models and contributed to sustainable manufacturing [102]. Krimpenis and Fountas [103] studied the multi-objective machining optimization problem based on a genetic algorithm and examined the influence of the key machining parameters of $\mathrm{CNC}$ machining operations. The different stages of the machine tools were introduced [104], including Machine 1.0, Machine 2.0, Machine 3.0, and detailed key features of Machine 4.0, such as network physics machines and vertical and horizontal integrated machine tools. Jeon and $\mathrm{Ha}$ [105] proposed a general method for generating the velocity distributions for acceleration and deceleration techniques for CNC machine tools. A proportion integration differentiation iterative learning controller for the CNC machine tools to perform repetitive tasks was proposed in Ref. [106]. Keller et al. [107] conducted a study on the reliability and maintainability of CNC machine tools after analyzing the field fault data of $35 \mathrm{CNC}$ machine tools. Yamato et al. [108] built an automatic flutter suppression system for parallel turning, integrating on-line flutter monitoring based on the cutting force estimation.

At present, the research on $\mathrm{CNC}$ machine tools mainly focuses on fault diagnosis, error compensation, parameter optimization, etc., which greatly improve the fault diagnosis efficiency and the machining accuracy of CNC machine tools. The research on CNC machine tools would also be extended to online real-time monitoring of products, smart machine tools, and green manufacturing.

The cold heading machine is a type of machine tool that uses a mold and a punch to make a part from a wire. The 
force driven by the punch pushes the material from the mold into a new shape [109]. Li et al. [110] revealed the mechanical behavior and the dynamic response of the cold heading machine and designed a new type of cold head force polyvinylidene fluoride piezoelectric film force sensor. The sensor has excellent dynamic performance and high precision measurement deformation ability. The multi-station cold heading machine is an automated, highprecision forming equipment widely used in manufacturing for the mass production of bolts and nuts. The reliability of the cold heading machine would affect the quality of the processed product and the processing efficiency [111]. Cold heading machines should meet the needs of a lowcarbon economy [112]. The research team of Shanghai University developed the first servo cold heading machine tool in China, which opened a new direction for the cold heading machine tool development.

3.1.1.2 Industrial robotics The automation and intelligence of manufacturing are inseparable from the application of industrial robots, which are widely used in all aspects of manufacturing. With the development of the manufacturing industry, the types and functions of industrial robots are becoming more diverse. In the process of traditional manufacturing to intelligent manufacturing, industrial robots would also usher in a new and greater development.

In recent years, an increasing number of researchers have been working on industrial robots. Some industrial robots must be taught before application to ensure efficiency. A scheme was proposed to minimize external force estimation errors and reduce guidance task interference by using virtual mass and virtual friction models for the manual teaching of industrial robots without force sensors [113]. The accuracy of industrial robots is affected by the uncertain parameters of link size and joint clearance deviation. Pérez et al. [114] studied the synergy between virtual reality and robots to create a fully immersive environment based on virtual reality, thereby improving the efficiency of the training and simulation process and providing a cost-effective solution. Industrial robots can submit efficiency and precision through teaching and training. In addition, they may also experience problems, such as loss of posture during exercise. An interval method was used to analyze the motion response of industrial robots with uncertain, but bounded parameters [115]. A path planning method was proposed to ensure that the floating base reached the predetermined attitude when the end-effector of the space-based $n$-joint manipulator moved to the predetermined position [116]. An improved omnidirectional mobile industrial robot tracking and localization algorithm could be proposed to solve the problem of attitude loss in motion. Industrial robots are inconvenient in the exchange of programming information for different processing projects, and integration is difficult [117]. Slavkovic et al. [118] introduced an indirect method for industrial robot programming for machining tasks, saving machining project information in a standard for exchange of product model data-numerical control format for an easy exchange between different users for machining. A tool path generation method based on a network model was studied and integrated into the offline robot programming system to provide a comprehensive solution for robot modeling, simulation, and tool path generation [119]. Some researchers used modeling software to simulate the structure of industrial robots using the finite element method. Berg et al. [120] studied an interaction concept that uses tracking of gestures and eyes to achieve a path to the robotic system and through projection to achieve a channel from the robotic system. Norrlof [121] studied an adaptive iterative learning control algorithm based on the estimation process and quadratic criterion optimization using the Kalman filter and successfully applied in industrial robots. In addition, research on underactuated robots has made great progress [122-124].

The research on industrial robots makes industrial robots more competitive in an application. With higher precision, smaller error, more reasonable structure, more convenient programming, and more friendly human-computer interaction, industrial robots are becoming increasingly important in industrial applications.

3.1.1.3 Special equipment Special equipment includes mining machinery, oil drilling equipment, special metallurgical equipment, and other special equipment. Researchers studied the use of hydrogen as a fuel in mining machinery to meet sustainability requirements [125]. Islam et al. [126] studied the vibration problem of holding oil and gas through simulation experiments. Andreev et al. [127] studied the technical parameters of the complex non-furnace treatment of blast furnace cast iron by the pulsating inert gas injection method, which significantly increased the operation resistance of metallurgical equipment.

\subsubsection{Intelligent manufacturing production line}

The intelligent manufacturing line consists of a series of precisely arranged intelligent manufacturing units that could be processed more flexibly and intelligently. Indri et al. [128] researched on a new paradigm of production lines based on three different sensor development methods characterized by a high degree of flexibility. The thin-film solar cell production line production capacity is low. The low-pressure chemical vapor deposition (LPCVD) is the main process leading to low productivity. To solve this problem, a method of prioritizing the LPCVD process work 
list was proposed, which greatly increased the production capacity and prolonged the service life of the device [129]. A task scheduling strategy was proposed based on a hybrid heuristic algorithm after studying the task scheduling strategy of fog computing, which solved the problem of limited computing resources and high energy consumption in intelligent production lines [130]. A large number of simulation experiments are required to reduce cost and save time before a production line is put into use. The intelligent production line fully verifies the availability of the production line by communicating with the external real programmable logic controller. The genetic algorithmbased approach is applied to the overhead shuttle (OHS) system design of flat panel display production lines [131]. To solve the problem of low efficiency and poor model quality of the production line modeling method, the concept of the digital twin production line was proposed, and the real-time modeling and simulation method of the digital twin production line were studied [132]. Its effectiveness was verified on the product assembly line. Research on intelligent manufacturing production lines still mainly focused on improving productivity. However, a few studies also combined virtual platforms, such as production lines and digital twin, which will be a research direction in the future.

\subsection{Sustainable intelligent manufacturing system}

The intelligent manufacturing system is a human-machine integrated intelligent system composed of intelligent machines and experts. According to different processing methods, intelligent manufacturing systems could be divided into process manufacturing systems and discrete manufacturing systems. According to the product life cycle process, discrete intelligent systems could be introduced from four aspects: design (e.g., low carbon design [133]), production, logistics, and sales. This section introduces intelligent manufacturing systems.

\subsubsection{Process manufacturing system}

Process manufacturing refers to the process in which the processed object continuously passes through the production equipment, and the raw materials are physically or chemically changed to finally obtain the product. The process manufacturing system refers to the production system applied to the process manufacturing process and is widely used in the petroleum and chemical industries. Three generations of systems can produce three products at the same time, but their processing units are susceptible to failure. Accordingly, an integration framework was proposed to solve the research on the three generations of palm-based biomass [134]. A mesoscale simulation method was proposed for heavy oil petroleum structural units and dissipative ion dynamics and used to simulate various heavy oil petroleum systems [135].

Research on process manufacturing systems focused on the petrochemical industry. Future research will focus on intelligence, safety, and efficiency.

\subsubsection{Discrete manufacturing system}

Discrete manufacturing systems refer to products that are made up of many independently machined parts ultimately assembled into a system of products. This section introduces discrete manufacturing systems from the perspective of the product life cycle, from design, production, logistics, and sales.

3.2.2.1 Design The design could be divided into conventional and innovative designs.

(i) Conventional design

Given that existing computer-aided design systems do not effectively provide the proper use of geometric tolerances, Lemu [136] proposed an algorithm development solution to achieve appropriate tolerances and conditions for use during the design specification phase. The facial prosthesis system based on computer-aided design/computer-aided manufacturing (CAD/CAM) was developed for the manufacture of facial prosthesis [137]. Lv and Lin [138] developed a real-time operational planning system in a distributed manufacturing network that significantly reduced planned workload. Gu et al. [139] studied the design of a multi-stage reconfigurable manufacturing system and measured the production loss, throughput stabilization time, and total production shortage time. Maturana et al. [140] proposed MetaMorph, an adaptive multi-agent manufacturing system architecture for dynamically creating and managing agent communities.

(ii) Innovative design

He et al. [141-147] used intelligent feature- and modelbased methods, spatial matrix, parametric, and other methods for intelligent design. The intelligent design system was used in the design process of the product, making the design process more efficient with a higher precision [148], a smaller error, and more sustainability [149] and generally requiring a computer-aided design system. A low-carbon design method based on carbon footprint was also proposed for product design [150-154]. Gregor et al. [155] created the Zilina Intelligent Manufacturing System expected to create an integrated collaborative environment that connected real, digital, and virtual. A low-carbon 
design method based on carbon footprint is also proposed for product design.

Research on intelligent design systems has made the design process more standardized, thereby greatly reducing workload and improving efficiency [156]. However, the current intelligent design system still has some shortcomings. The current intelligent design system is not intuitive in the design process. Therefore, integration with the virtual reality technology and the collaborative design [157] would be the key research direction of the next stage.

3.2.2.2 Production Intelligent production systems are used in the processing of products, optimizing the processing steps of products, and improving the resource utilization, adaptability, and robustness of manufacturing systems. Manufacturing could be divided into two processes: machining and assembly.

\section{(i) Machining}

Simeone et al. [158] proposed an intelligent cloud manufacturing platform for sheet metal cutting services that increased the utilization of supplier resources to $92.3 \%$. The intelligent immune system for energy-saving manufacturing can achieve an energy savings of approximately $30 \%$ in the factory and increase the production efficiency by more than 50\% [159]. Stadnicka et al. [160] analyzed the role of humans in intelligent manufacturing systems and proposed innovative ways to learn how to simulate a virtual reality to transfer knowledge of intelligent manufacturing systems. In addition, considering the low carbon requirements in the production process will save more energy [161]. Tao et al. [162] proposed a cloud manufacturing service system and a framework based on the IoTs and cloud computing. They also analyzed the relationship between the two. An advanced manufacturing IoT intelligent manufacturing platform was designed based on IoTs, cloud computing, big data analysis, network physics system, and prediction technology. This platform was then applied to the bumping process of semiconductor companies. The application results showed that the platform could perform comprehensive inspections in production [163]. He et al. [164] put forward a new method of constraint mechanism function synthesis based on system dynamic programming, which was applied to the offshore platform jacking system. A network physics system based on multiagent technology was developed and applied to the manufacturing workshop to improve the reconfigurability and responsiveness of the workshop [165]. Lee et al. [166] proposed the industrial IoT suite to run high value-added manufacturing processes, implement intelligent production, and achieve re-industrialization in Hong Kong. These studies effectively improved resource utilization and production efficiency. Other studies focused on sustainability
[167] and in rationalizing the processing steps to make the process meet sustainability requirements.

Helo et al. [168] developed a cloud-based distributed manufacturing execution system to address the needs and challenges of managing distributed manufacturing in a multi-company supply chain. The architecture of intelligent manufacturing systems was proposed based on distributed artificial intelligence to shorten the product development cycle [169]. The structure of the intelligent chemical industry network physical system was proposed and applied to the intelligent distillation tower [170]. The operation results showed that stability and robustness met the requirements.

Resource-intelligence and access systems were developed based on the IoTs to realize the manufacturing model of cloud manufacturing [171]. Jain et al. [172] developed a digital twin model that implemented an estimate of the measurable characteristic output of a photovoltaic energy conversion unit. Based on this model, 10 different faults, power converters, and electronic sensor faults were detected and identified in the photovoltaic energy conversion unit. The detection and identification times were less than $290 \mu \mathrm{s}$ and $4 \mathrm{~ms}$, respectively. Moreover, the fault detection and recognition time in the distributed photovoltaic panels were less than $80 \mathrm{~ms}$ and $1.2 \mathrm{~s}$, respectively.

\section{(ii) Assembly}

An IoT intelligent assembly system framework was proposed based on the information and communication technology, sensor networks, and radio frequency identification and applied to the assembly process of mechanical products [173]. Research on the intelligent production system based on the agent technology can effectively improve the system adaptability. An agent-based manufacturing system architecture was proposed for application to hybrid multiproduct production to improve the adaptability and robustness of the manufacturing system [174]. Chaplin et al. [175] designed evolvable assembly systems using the intelligent agent technology and data distribution services. Intelligent production systems can be developed based on distributed technologies to shorten the development cycle. Intelligent production systems for specific product research meet specific production needs. Wang [176] introduced the general framework of a zero-defect manufacturing system and introduced the application of zero-defect manufacturing methods to create zero-defect products. The network physical system architecture of the intelligent manufacturing workshop was proposed, and it verified the feasibility of the architecture on a small flexible automated production line [177]. A custom-oriented intelligent manufacturing system was proposed, and a customizable candy production system was established [178]. A labeling and management framework was proposed for steel label 
characters, while a method for the online monitoring and tracking of marker characters based on machine vision was proposed to realize information management and intelligent manufacturing for steel manufacturing [179]. A knowledge-based intelligent system for diagnosing webbased management was studied, and its defects increased the wafer manufacturing throughput [180]. Specific intelligent production systems enable agile manufacturing and reduce the probability of defects.

3.2.2.3 Logistics The intelligent logistics system is applied to the traceability of product processing and the management of product logistics information. Strandhagen et al. [181] studied Industry 4.0 for manufacturing logistics. The study of four Norwegian manufacturing companies showed that the practicality of Industry 4.0 in manufacturing logistics depended on the production environment. A food traceability network physical system method based on intelligent value stream was proposed to improve the efficiency of the food traceability system [182]. Maoudj et al. [183] developed a distributed multi-agent system for scheduling and controlling robotic flexible assembly units. The production data are collected in real time for product traceability based on the intelligent logistics system developed by the radio frequency identification technology [184-188], realizing the production management and dynamic scheduling of the workshop. The intelligent logistics system realizes the logistics function in intelligent manufacturing and can track the status and logistics information of the product in real time to realize dynamic scheduling.

3.2.2.4 Sales The intelligent sales system is used to sell manufactured products and manage sales information for intelligent sales. A vehicle sales integrated management system was studied. It can manage vehicle sales in a unified manner and input real-time information into mobile devices with high security [189].

Take the marketing module of a company's collaborative manufacturing system as an example. The module has the functions of entering order information, querying order information, and managing customer information for entering and managing order information. After the salesperson obtains the order, the order information is entered into the system, and the order information could then be queried and managed.

\subsection{Sustainable intelligent manufacturing services}

Intelligent manufacturing services for intelligent manufacturing have a wide range of applications. This section introduces intelligent manufacturing services from three aspects: product development, manufacturing, and after sales services (see Fig. 3). Sustainable intelligent manufacturing service contains product development, manufacturing, and after sales services, which support each other.

\subsubsection{Product development services}

The product development service in the intelligent manufacturing service mainly serves the whole process of product development, making the development process simple and efficient. This part includes collaborative design service, product customization service, and so on.

\subsubsection{Collaborative design service Collaborative} design service mainly provides a platform to integrate people with design requirements and capabilities. When someone has design requirements, they can publish the requirements to the platform. People with design capabilities can undertake the requirements and participate in the design together. Zhang et al. [190] proposed an intelligent manufacturing integration system that was applied to the projects they participated in and achieved good results. He et al. [191] proposed sustainable supply chain design model. Sun et al. [192] studied the security of networked control systems. McFarlane et al. [193] explored the impact of automatic identification systems on the intelligent control of manufacturing plants. To solve the layout optimization problem of the multi-module satellite equipment, a two-system co-evolution algorithm based on the bode coevolution framework was proposed [194]. Malik and Bilberg [195] proposed a digital and physical medical workspace that combined the digital and physical worlds for collaborative design. To solve the problems in distributed collaborative design system of complex products, a group global search and negotiation algorithm based on fuzzy matter-element particle swarm optimization was proposed [196].

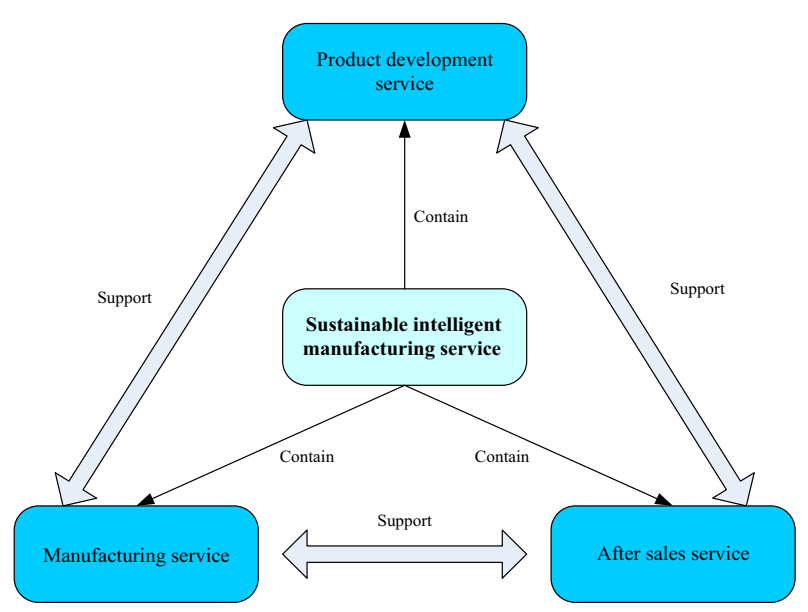

Fig. 3 Three aspects of intelligent manufacturing service 
3.3.1.2 Product customization service A large-scale personalized production framework based on the concept of Industry 4.0 was proposed and realized large-scale personalized production in industrial practice [197]. Rødseth et al. [198] developed a new model of deep digital maintenance based on network physics systems and maintenance theory to achieve integrated planning. To achieve a new approach to personalization and customization, researchers are rapidly deploying resources based on manufacturing services [199-204].

3.3.1.3 Other services The performance estimation model-based optimization algorithm was studied [205] and applied to large-scale complex manufacturing system simulations [206], reducing the run time by more than $7 \%$. A product lifecycle management application framework based on the digital twin was proposed [207]. A viewbased 3D CAD model reuse framework was proposed to enable the effective reuse of 3D CAD models in the product life cycle [208]. He et al. [209] used the low-carbon concept to optimize the structure of the product to meet the low carbon requirements. Bodrow [210] proposed an application scenario for knowledge visualization to test the expertise and demonstrated its usefulness in intelligent software applications for process control. Giret et al. [211] proposed a specific software engineering approach to help developers develop a sustainable intelligent manufacturing system, called Go-green ANEMONA. A graph-based knowledge reuse method was proposed to support knowledge-driven decision making in product development, reuse the knowledge already in the manufacturing industry, and improve the product innovation quality [212].

Through research on intelligent development services, the running time of the complex manufacturing system simulation is shortened, and the accuracy and the real-time performance of online monitoring systems are improved, making product development easier.

\subsubsection{Manufacturing service}

Manufacturing services mainly include intelligent monitoring, intelligent control, and collaborative manufacturing.

3.3.2.1 Intelligent monitoring A 3D visual monitoring system for production lines based on OpenGL modeling on the $\mathrm{VC}++6.0$ platform was established to meet effective production [213]. A grey online modeling surface roughness monitoring system was developed to accurately predict the surface roughness in end milling [214]. Machine center fault diagnosis and prediction based on data mining were studied to develop a systematic approach and obtain predictive maintenance knowledge in the Industry 4.0 era [215]. The manufacturing service in the intelligent manufacturing service mainly serves the whole process of product processing and manufacturing and provides services, such as monitoring, scheduling, online monitoring, sustainable manufacturing, and real-time warning for product processing. Kim and Hwangbo [216] developed an intelligent real-time early warning system for plastic film production with a prediction accuracy close to $100 \%$.

3.3.2.2 Intelligent control An intelligent decision support system architecture based on radio frequency identification was proposed for processing production monitoring and scheduling in a distributed manufacturing environment [217]. Tan et al. [218] proposed an embedded adaptive network service framework [219] and applied this to networked manufacturing systems. A browser-serverterminal model is proposed to realize remote control of embedded terminal devices, and a new method of remote control of embedded terminal devices is proposed [220]. Theorin et al. [221] proposed a line information system architecture for flexible plant integration and data applications. A mapping-based computational experimental approach was proposed and used to solve the complexity of the construction and development of the manufacturing service ecosystem and analyze the evolution of the manufacturing service ecosystem [222].

3.3.2.3 Collaborative manufacturing In addition, for the problem of close contact between users and manufacturers, a synergistic-based service combination approach can be used to connect users to manufacturers and make full use of resources to create a collaborative manufacturing platform [223-228].

Take an equipment collaborative manufacturing system as an example to illustrate the intelligent manufacturing service [229]. The equipment collaborative manufacturing system is a collaborative manufacturing platform that integrates customers, experts, and manufacturing companies. The customers are provided with collaborative design and collaborative manufacturing services. When customers have design or manufacturing requirements, but do not have the conditions for completion, they can post demand orders on the platform, describe the requirements in detail, provide the necessary documentation, and wait for experts or a manufacturing company to accept the order.

For a company, when a customer issues a demand order, the company first reviews and evaluates whether it can complete the order. If yes, it directly accepts the order, directly connects with the customer, and no longer publishes it on the platform; otherwise, the order will be sorted out. The order is then released to the platform for experts or manufacturing companies that cooperate with the platform. A platform for experts or manufacturing companies to undertake design or manufacturing orders is provided. 
When an expert or a manufacturing company finds an appropriate order on the platform, it can apply for the order. They can then establish contact on the platform after the platform administrator approves the application. Such an equipment collaborative manufacturing system integrates customers, experts, and manufacturing companies into a closed loop of manufacturing, thereby providing intelligent services to customers, experts, and manufacturing companies and enabling them to benefit from them.

With the increasing use of cloud applications, technologies, such as cloud manufacturing and cloud services, can be applied to the after-sales service of intelligent manufacturing services. A dynamic ant colony genetic hybrid algorithm was proposed for solving large-scale cloud service composition and optimization problems [230]. A multi-objective hybrid artificial bee colony algorithm was proposed for service composition and optimization selection in cloud manufacturing [231]. An offline $3 \mathrm{D}$ automated printer approach to enhance the competitiveness of 3D printing was developed based on the cloud manufacturing service model and the 3D printing cloud service platform [232]. The optimal choice of a cloud service portfolio in cloud manufacturing was studied, and a cloud service category and a service quality index were established [233]. The agent-based manufacturing service discovery framework was studied. This framework consists of an object- and model-based manufacturing task agent, a manufacturing service agent, and task and service matching process knowledge base to realize the manufacturing service discovery in a cloud manufacturing environment [234]. The development of the cloud manufacturing service platform provides technical support. A cloud manufacturing service platform for small- and medium-sized enterprises, which implements semantic intelligence search, order tracking, event task guidance, and collaborative management, was developed [235].

\subsubsection{After-sales service}

After-sales service mainly includes fault diagnosis and maintenance.

3.3.3.1 Fault diagnosis DeSmit et al. [236] studied a method for systematically identifying network physical vulnerabilities in intelligent manufacturing systems. This method can analyze the potential impact of vulnerabilities in intelligent manufacturing systems. Fault diagnosis and prediction of wind turbines based on supervisory control and data acquisition (SCADA) data were studied, and an artificial intelligence-based framework was proposed for wind turbine fault diagnosis and prediction using the SCADA data [237]. A neighborhood enhancement matrix decomposition method was proposed to predict the loss of the service quality value of the cloud manufacturing service platform [238]. Lartigau et al. [239] proposed a service quality assessmentbased approach for transport impact analysis.

3.3.3.2 Fault maintenance The interstitial error data interpretation and the compensation of machine center intelligent predictive maintenance were studied based on an artificial neural network [240]. The research results showed that the gap error in the front and back directions of the machining center could be predicted and compensated. Liu and Ming [241] proposed a framework for the revision of the rough Decision Making Trial and Evaluation Laboratory method for capturing and evaluating intelligent industrial product service systems.

The after-sales service research includes fault warning, fault diagnosis, quality maintenance, and cloud-based after-sales service. Fault warning and diagnosis enable the user to grasp the status of the product in real time and take corresponding measures according to the feedback in time, which greatly increases the service life of the product.

\section{Framework of digital twin-driven sustainable intelligent manufacturing}

This study proposed the framework of digital twin-driven sustainable intelligent manufacturing (see Fig. 4).

Digital twin-driven sustainable intelligent manufacturing consists of a basic platform, sustainable intelligent manufacturing equipment, sustainable intelligent manufacturing system, and sustainable intelligent manufacturing service. Among them, the basic platform is mapped with sustainable intelligent manufacturing equipment, sustainable intelligent manufacturing system, and sustainable intelligent manufacturing service. The sustainable intelligent manufacturing equipment, sustainable intelligent manufacturing system, and sustainable intelligent manufacturing service support each other. Sustainable intelligent manufacturing platforms could be interconnected to integrate the value chain among enterprises and form a new industrial form.

The data of the basic platform comes from the equipment layer of the platform, which includes equipment, unit, production line, and production workshop. After the platform obtains data from the device layer, it combines cloud computing, artificial intelligence, IoTs, and other technologies. It then comprehensively considers environmental, economic, and social factors and combines human, equipment, and technology to provide data for virtual and physical prototyping. Virtual and physical prototyping map with sustainable intelligent manufacturing equipment, sustainable intelligent manufacturing systems, and sustainable intelligent manufacturing services. 


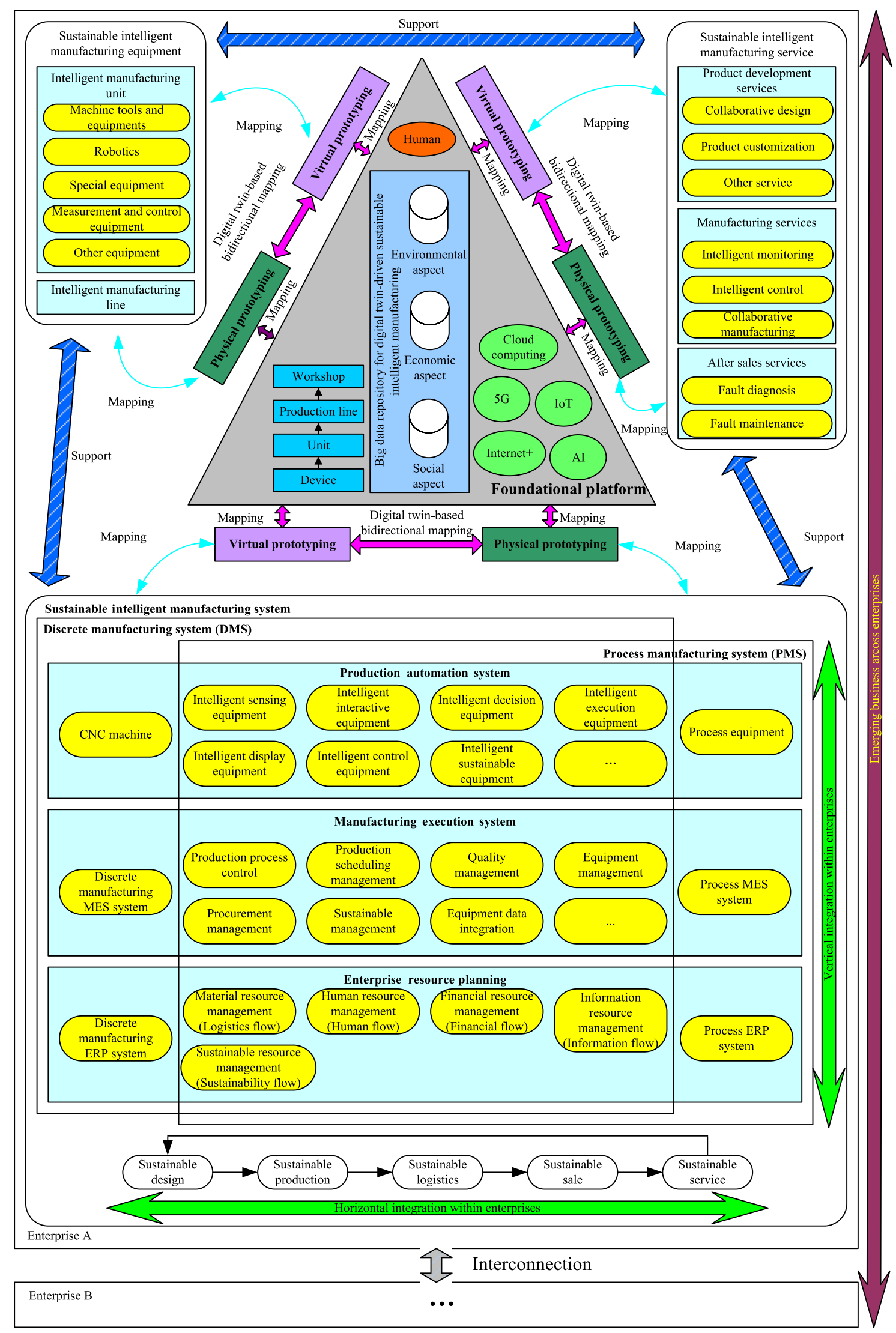

Fig. 4 Framework of digital twin-driven sustainable intelligent manufacturing 
Sustainable intelligent manufacturing equipment includes an intelligent manufacturing unit and an intelligent manufacturing production line. The intelligent manufacturing unit includes machine tools, robots, special equipment, measurement and control equipment, and other equipment. Sustainable intelligent manufacturing equipment maps to virtual and physical prototyping.

The sustainable intelligent manufacturing system includes a discrete manufacturing system and a process manufacturing system. In the horizontal direction, the sustainable intelligent manufacturing system could be divided into sustainable design, sustainable production, sustainable logistics, sustainable sales, and sustainable services and form a sustainable closed loop. In the vertical direction, it could be divided into automatic production system, manufacturing execution system, and enterprise resource management. Discrete and process manufacturing systems overlap and differ in all directions.

Sustainable intelligent manufacturing service includes product development, manufacturing, and after-sales services. Product development services include collaborative design, product customization, and others. Manufacturing services include intelligent monitoring, intelligent control, and collaborative manufacturing. After-sales service includes fault diagnosis and maintenance.

\section{Future works}

It is gradually phasing out the industry with a heavy environmental burden. Developing intelligent manufacturing with increasing attention on sustainability is vigorous. Sustainability is paid increasing attention, thereby clearly positioning the sustainable development of the manufacturing industry as the foundation. Sustainable intelligent manufacturing plays an irreplaceable role. Several future works are needed in this topic.

\subsection{Framework of sustainable intelligent manufacturing}

\section{(i) Sustainable intelligent design}

The design is the foundation of intelligent manufacturing; therefore, the traditional design must urgently be upgraded to a sustainable intelligent design to achieve sustainable intelligent manufacturing. Virtual and physical prototyping could be interconnected in real time at the design stage. Achieving a sustainable design for the sustainable supply chain is also important.

(ii) Comprehensive sustainability

The concept of sustainability has become an important topic [242-244], and combining sustainable concepts with intelligent manufacturing to achieve sustainable intelligent manufacturing is an important future research direction. As a sustainable technology, it could reduce emissions in the life cycle of products, thereby achieving the requirements of both intelligent manufacturing and comprehensive sustainability from the perspective of environmental, economic, and social aspects.

(iii) Sustainable intelligent manufacturing for the product life cycle

Sustainable intelligent manufacturing for the product life cycle, including design, production, logistics, sale, and service, must be achieved. The virtual and augmented realities could be also used in the product life cycle.

(iv) Sustainable intelligent manufacturing across enterprise value chain

The interconnection among enterprises could be more universal; thus, the intelligent manufacturing could pay more attention on the enterprise value chain.

(v) Sustainable intelligent manufacturing for product environmental footprint

The massive emissions of greenhouse gases, especially carbon dioxide, have led to increasing global warming. Therefore, cleaner production is receiving global attention in the manufacturing industry. The industry is responsible for producing products in an environmentally friendly manner. The European Union (EU) proposes the use of the product environmental footprint [245, 246], including 14 types of environmental factors (e.g., product carbon footprint, product water footprint, etc.) to simulate the environmental impact of the emissions generated during the product life cycle. The environmental impact of manufacturing is becoming increasingly serious. Hence, the challenges of improving production efficiency and reducing carbon footprint during the product life cycle are receiving increasing attention [247]. In studying the intelligent manufacturing of the carbon footprint of products, one must consider the carbon emissions of products from raw materials, processing, transportation, use, recycling, etc., to guide the development of intelligent manufacturing. To achieve clean manufacturing, low-carbon manufacturing is a future research direction.

(vi) Human-machine collaboration

Human and machine could interact with each other more collaboratively in sustainable intelligent manufacturing, which enables a human to have efficient and effective decision-making with machines.

(vii) Sustainable intelligent manufacturing equipment, sustainable intelligent manufacturing system, and sustainable intelligent manufacturing service 


\subsection{Enabling technology of sustainable intelligent manufacturing}

(i) Digital twin-based big data-driven sustainable intelligent manufacturing

With the implementation of intelligent manufacturing, manufacturing precision, product quality, and processing efficiency would continuously improve. With the help of the digital twin and big data technologies, a virtual simulation model of the solid model would be established, and the entity status could be fed back in real time. The digital twin could be applied to online real-time product inspection and equipment fault diagnosis and repair.

(ii) Artificial intelligence-driven sustainable intelligent manufacturing

Information technology has achieved rapid development since the beginning of the 21 st century. In recent years, artificial intelligence has rapidly developed in the aspects of medical, monitoring, and interaction, thereby greatly changing people's lifestyles. In the future, the intelligent manufacturing process would inevitably reduce the human factor. Therefore, applying artificial intelligence to intelligent manufacturing, gradually replacing the role of human beings, and realizing unmanned intelligent manufacturing will be the future research direction.

(iii) IoTs-driven sustainable intelligent manufacturing The Internet of Things enables all objects that could perform independent functions to be connected to the network, thereby enabling interconnection and interoperability to achieve the effect of the Internet of everything. Combining IoTs with intelligent manufacturing enables the production equipment and production products to be interconnected. The equipment can independently sense the processing quality of the products and make timely adjustments to achieve independent production.

\subsection{Application of sustainable intelligent manufacturing}

Sustainable intelligent manufacturing must be put into applications. For process intelligent manufacturing systems, such as those used in the steel, pharmaceutical, and petrochemical industries, and for the discrete intelligent manufacturing system, such as that used in the mechanical manufacturing industry, the MES could play an important role in the manufacturing system.

\section{Conclusions}

With the transformation and upgrade of manufacturing, sustainable intelligent manufacturing has become increasingly important. Intelligent manufacturing combined with a digital twin has the functions of intelligent sensing and simulation, which makes the production of products more efficient and intelligent. At the same time, it could monitor the status of products and production equipment in real time and predict possible failures in time. After the introduction of a digital twin and its application, three aspects of digital twin-driven sustainable intelligent manufacturing, namely sustainable intelligent manufacturing equipment, sustainable intelligent manufacturing systems, and sustainable intelligent manufacturing services, were introduced. The framework of the digital twin-driven sustainable intelligent manufacturing was proposed in detail. The future direction of digital twin-driven sustainable intelligent manufacturing was also discussed.

Acknowledgements The work was supported by the National Natural Science Foundation of China (Grant No. 51675319), and Shanghai Science and Technology Committee Project (Grant No. 19511104702).

Open Access This article is licensed under a Creative Commons Attribution 4.0 International License, which permits use, sharing, adaptation, distribution and reproduction in any medium or format, as long as you give appropriate credit to the original author(s) and the source, provide a link to the Creative Commons licence, and indicate if changes were made. The images or other third party material in this article are included in the article's Creative Commons licence, unless indicated otherwise in a credit line to the material. If material is not included in the article's Creative Commons licence and your intended use is not permitted by statutory regulation or exceeds the permitted use, you will need to obtain permission directly from the copyright holder. To view a copy of this licence, visit http://creativecommons. org/licenses/by/4.0/.

\section{References}

1. Waschull S, Bokhorst JAC, Molleman E et al (2020) Work design in future industrial production: transforming towards cyber-physical systems. Comput Ind Eng. 139:105679

2. Javed Y, Felemban M, Shawly T et al (2019) A partition-driven integrated security architecture for cyber-physical systems. arXiv: 190103018 [csSY]

3. Van Der Zeeuw A, Van Deursen AJ, Jansen G (2019) Inequalities in the social use of the internet of things: a capital and skills perspective. New Media Soc 21(6):1344-1361

4. Habibi M, Fazli M, Movaghar A (2019) Efficient distribution of requests in federated cloud computing environments utilizing statistical multiplexing. Future Gener Comput Syst 90:451-460

5. Yan H, Yu P, Long D (2019) Study on deep unsupervised learning optimization algorithm based on cloud computing. In: 2019 international conference on intelligent transportation, Big data \& smart city (ICITBS), pp 679-681

6. He B, Pan QJ, Deng ZQ (2018) Product carbon footprint for product life cycle under uncertainty. J Clean Prod 187:459-472 
7. Radhi H (2019) Multi-objective optimization of turning process during machining of AISI 1025 on CNC machine using multiobjective particle swarm optimization. Univ Thi-Qar J Eng Sci 10(1):65-70

8. He B, Cao XY, Gu ZC (2020) Kinematics of underactuated robotics for product carbon footprint. J Clean Prod 257:120491

9. Chiaverini S, Siciliano B, Egeland O (1994) Review of the damped least-squares inverse kinematics with experiments on an industrial robot manipulator. IEEE Trans Control Syst Technol 2(2):123-134

10. Altintas Y, Yang J, Kilic ZM (2019) Virtual prediction and constraint of contour errors induced by cutting force disturbances on multi-axis CNC machine tools. CIRP Ann 68(1):377-380

11. Zheng P, Wang HH, Sang ZQ et al (2018) Smart manufacturing systems for Industry 4.0: conceptual framework, scenarios, and future perspectives. Front Mech Eng 13(2):137-150

12. Tao F, Qi QL, Liu A et al (2018) Data-driven smart manufacturing. J Manuf Syst 48:157-169

13. Zhong RY, Xu X, Klotz E et al (2017) Intelligent manufacturing in the context of Industry 4.0: a review. Engineering 3(5):616-630

14. Yadav A, Jayswal SC (2017) Modelling of flexible manufacturing system: a review. Int J Prod Res 56(7):2464-2487

15. Li BH, Hou BC, Yu WT et al (2017) Applications of artificial intelligence in intelligent manufacturing: a review. Front Inf Technol Electron Eng 18(1):86-96

16. Kusiak A (2017) Smart manufacturing. Int J Prod Res 56(1/ 2):508-517

17. He B, Hua YC (2017) Feature-based integrated product model for low-carbon conceptual design. J Eng Des 28(6):408-432

18. Bouzary H, Frank Chen F (2018) Service optimal selection and composition in cloud manufacturing: a comprehensive survey. Int J Adv Manuf Technol 97(1/4):795-808

19. Bouzary H, Chen FF, Krishnaiyer K (2018) Service matching and selection in cloud manufacturing: a state-of-the-art review. Procedia Manuf 26:1128-1136

20. Bauer D, Stock D, Bauernhansl T (2017) Movement towards service-orientation and app-orientation in manufacturing it. Procedia CIRP 62:199-204

21. Giret A, Garcia E, Botti V (2016) An engineering framework for service-oriented intelligent manufacturing systems. Comput Ind $81: 116-127$

22. Cao Y, Wang SL, Kang L et al (2015) Study on machining service modes and resource selection strategies in cloud manufacturing. Int J Adv Manuf Technol 81(1/4):597-613

23. He B, Zhang D, Gu ZC et al (2020) Skeleton model-based product low carbon design optimization. J Clean Prod. https:// doi.org/10.1016/j.jclepro.2020.121687

24. Grossmann IE (2019) Optimization and management in manufacturing engineering: resource collaborative optimization and management through the internet of things. Optim Methods Softw 34(1):220-223

25. Soni R, Bhatia M, Singh T (2019) Digital twin: intersection of mind and machine. Int J Comput Intell IoT 2(3):667-670

26. Zheng P, Lin Y, Chen CH et al (2018) Smart, connected open architecture product: an IT-driven co-creation paradigm with lifecycle personalization concerns. Int $\mathrm{J}$ Prod Res 57(8):2571-2584

27. Nikolakis N, Alexopoulos K, Xanthakis E et al (2019) The digital twin implementation for linking the virtual representation of human-based production tasks to their physical counterpart in the factory-floor. Int J Comput Integr Manuf 32(1):1-12

28. Wang SY, Wan JF, Zhang DQ et al (2016) Towards smart factory for Industry 4.0: a self-organized multi-agent system with big data based feedback and coordination. Comput Netw 101:158-168

29. Grieves M (2014) Digital twin: manufacturing excellence through virtual factory replication. White paper, pp 1-7

30. Abdulmotaleb ES (2018) Digital twins: the convergence of multimedia technologies. IEEE Multimed 25(2):87-92

31. Negri E, Fumagalli L, Macchi M (2017) A review of the roles of digital twin in CPS-based production systems. Procedia Manuf 11:939-948

32. Chhetri MB, Krishnaswamy S, Loke SW (2004) Smart virtual counterparts for learning communities. In: Bussler $\mathrm{C}$ et al (eds) Web information systems-WISE 2004 workshops, WISE 2004. Springer, Berlin, pp 125-134

33. Glaessgen E, Stargel D (2012) The digital twin paradigm for future NASA and U.S. Air force vehicles. In: 2012 53rd AIAA/ ASME/ASCE/AHS/ASC Structures, structural dynamics and materials conference, pp 1-14

34. Lee J, Bagheri B, Kao HA (2015) A cyber-physical systems architecture for Industry 4.0-based manufacturing systems. Manuf Lett 3:18-23

35. Söderberg R, Wärmefjord K, Carlson JS et al (2017) Toward a digital twin for real-time geometry assurance in individualized production. CIRP Ann 66(1):137-140

36. Bolton RN, McColl-Kennedy JR, Cheung L et al (2018) Customer experience challenges: bringing together digital, physical and social realms. J Serv Manag 29(5):776-808

37. Tao F, Sui FY, Liu A et al (2019) Digital twin-driven product design framework. Int J Prod Res. 57(12):3935-3953

38. Hu LW, Nguyen NT, Tao WJ et al (2018) Modeling of cloudbased digital twins for smart manufacturing with $\mathrm{mt}$ connect. Procedia Manuf 26:1193-1203

39. Tao F, Cheng JF, Qi QL et al (2017) Digital twin-driven product design, manufacturing and service with big data. Int $\mathbf{J}$ Adv Manuf Technol 94(9/12):3563-3576

40. Schleich B, Anwer N, Mathieu L et al (2017) Shaping the digital twin for design and production engineering. CIRP Ann 66(1):141-144

41. Haag S, Anderl R (2018) Digital twin—proof of concept. Manuf Lett 15:64-66

42. Guo JP, Zhao N, Sun L et al (2018) Modular based flexible digital twin for factory design. J Ambient Intell Hum Comput 10(3):1189-1200

43. Bao JS, Guo DS, Li J et al (2018) The modelling and operations for the digital twin in the context of manufacturing. Enterp Inf Syst 13(4):534-556

44. Cheng Y, Tao F, Xu LD et al (2016) Advanced manufacturing systems: supply-demand matching of manufacturing resource based on complex networks and internet of things. Enterp Inf Syst 12(7):780-797

45. Bilberg A, Malik AA (2019) Digital twin driven human-robot collaborative assembly. CIRP Ann 68(1):499-502

46. Um J, Weyer S, Quint F (2017) Plug-and-simulate within modular assembly line enabled by digital twins and the use of automation ML. IFAC-PapersOnLine 50(1):15904-15909

47. Qi QL, Tao F, Zuo Y et al (2018) Digital twin service towards smart manufacturing. Procedia CIRP 72:237-242

48. Leng JW, Zhang H, Yan DX et al (2018) Digital twin-driven manufacturing cyber-physical system for parallel controlling of smart workshop. J Ambient Intell Hum Comput 10(3):1155-1166

49. Cheng Y, Zhang YP, Ji P et al (2018) Cyber-physical integration for moving digital factories forward towards smart manufacturing: a survey. Int J Adv Manuf Technol 97(1/4):1209-1221

50. Meng SH, Tang SL, Zhu YH et al (2019) Digital twin-driven control method for robotic automatic assembly system. IOP Conf Ser Mater Sci Eng 493:012128 
51. Xiang F, Zhi Z, Jiang GZ (2018) Digital twins technology and its data fusion in iron and steel product life cycle. In: 2018 IEEE 15 th international conference on networking, sensing and control (ICNSC), pp 1-5

52. Zhang H, Liu Q, Chen X et al (2017) A digital twin-based approach for designing and multi-objective optimization of hollow glass production line. IEEE Access 5:26901-26911

53. Zhuang CB, Liu JH, Xiong H (2018) Digital twin-based smart production management and control framework for the complex product assembly shop-floor. Int J Adv Manuf Technol 96(1/ 4):1149-1163

54. Liu Q, Zhang H, Leng JW et al (2018) Digital twin-driven rapid individualised designing of automated flow-shop manufacturing system. Int J Prod Res 57:3903-3919

55. Liau Y, Lee H, Ryu K (2018) Digital twin concept for smart injection molding. IOP Conf Ser Mater Sci Eng 324:012077

56. Botkina D, Hedlind M, Olsson B et al (2018) Digital twin of a cutting tool. Procedia CIRP 72:215-218

57. Pairet È, Ardón P, Liu X et al (2019) A digital twin for humanrobot interaction. In: 2019 14th ACM/IEEE international conference on human-robot interaction (HRI), pp 372-372

58. Voinov N, Chernorutsky I, Drobintsev P et al (2017) An approach to net-centric control automation of technological processes within industrial IoT systems. Adv Manuf 5(4):388-393

59. Uhlemann THJ, Schock C, Lehmann C et al (2017) The digital twin: demonstrating the potential of real time data acquisition in production systems. Procedia Manuf 9:113-120

60. Coronado PDU, Lynn R, Louhichi W et al (2018) Part data integration in the shop floor digital twin: mobile and cloud technologies to enable a manufacturing execution system. J Manuf Syst 48:25-33

61. Schluse M, Priggemeyer M, Atorf L et al (2018) Experimentable digital twins - streamlining simulation-based systems engineering for Industry 4.0. IEEE Trans Ind Inf 14(4):1722-1731

62. Macchi M, Roda I, Negri E et al (2018) Exploring the role of digital twin for asset lifecycle management. IFAC-PapersOnLine 51(11):790-795

63. Kunath M, Winkler H (2018) Integrating the digital twin of the manufacturing system into a decision support system for improving the order management process. Procedia CIRP 72:225-231

64. Biesinger F, Meike D, Kraß B et al (2018) A case study for a digital twin of body-in-white production systems general concept for automated updating of planning projects in the digital factory. In: 2018 IEEE 23rd international conference on emerging technologies and factory automation (ETFA), pp 19-26

65. Vachálek J, Bartalský L, Rovný O et al (2017) The digital twin of an industrial production line within the Industry 4.0 concept. In: 2017 21st international conference on process control (PC), pp 258-262

66. Uhlemann THJ, Lehmann C, Steinhilper R (2017) The digital twin: realizing the cyber-physical production system for Industry 4.0. Procedia CIRP 61:335-340

67. Tao F, Zhang M (2017) Digital twin shop-floor: a new shopfloor paradigm towards smart manufacturing. IEEE Access 5:20418-20427

68. He B, Deng ZQ, Huang S et al (2014) Application of unascertained number for the integration of carbon footprint in conceptual design. Proc Inst Mech Eng J Eng Manuf 229(11):2088-2092

69. Martinez HV, Neely AD, Ouyang A et al (2019) Service business model innovation: the digital twin technology. EurOMA. https://doi.org/10.17863/CAM.35482
70. Liu Y, Zhang L, Yang Y et al (2019) A novel cloud-based framework for the elderly healthcare services using digital twin. IEEE Access 7:49088-49101

71. Balachandar S, Chinnaiyan R (2019) Reliable digital twin for connected footballer. In: International conference on computer networks and communication technologies. pp 185-191

72. Guivarch D, Mermoz E, Marino Y et al (2019) Creation of helicopter dynamic systems digital twin using multibody simulations. CIRP Ann 68(1):133-136

73. Tao F, Zhang M, Liu YS et al (2018) Digital twin driven prognostics and health management for complex equipment. CIRP Ann 67(1):169-172

74. Lynn R, Chen A, Locks S et al (2015) Intelligent and accessible data flow architectures for manufacturing system optimization. In: Umeda S, Nakano M, Mizuyama $\mathrm{H}$ et al (eds) Advances in production management systems: innovative production management towards sustainable growth. Springer, Berlin, pp 27-35

75. Luo W, Hu T, Zhang C et al (2018) Digital twin for CNC machine tool: modeling and using strategy. J Ambient Intell Hum Comput 10(3):1129-1140

76. Li CZ, Mahadevan S, Ling Y et al (2017) Dynamic bayesian network for aircraft wing health monitoring digital twin. AIAA J 55(3):930-941

77. Kaebernick H, Kara S, Sun M (2003) Sustainable product development and manufacturing by considering environmental requirements. Robot Comput Integr Manuf 19(6):461-468

78. Rusinko C (2007) Green manufacturing: an evaluation of environmentally sustainable manufacturing practices and their impact on competitive outcomes. IEEE Trans Eng Manag 54(3):445-454

79. Miller G, Pawloski J, Standridge CR (2010) A case study of lean, sustainable manufacturing. J Ind Eng Manag 3(1):11-32

80. Akbar M, Irohara T (2018) Scheduling for sustainable manufacturing: a review. J Clean Prod 205:866-883

81. Carvalho N, Chaim O, Cazarini E et al (2018) Manufacturing in the fourth industrial revolution: a positive prospect in sustainable manufacturing. Procedia Manuf 21:671-678

82. Gbededo MA, Liyanage K, Garza-Reyes JA (2018) Towards a life cycle sustainability analysis: a systematic review of approaches to sustainable manufacturing. J Clean Prod 184:1002-1015

83. Koren Y, Gu X, Badurdeen F et al (2018) Sustainable living factories for next generation manufacturing. Procedia Manuf 21:26-36

84. Stoycheva S, Marchese D, Paul C et al (2018) Multi-criteria decision analysis framework for sustainable manufacturing in automotive industry. J Clean Prod 187:257-272

85. Moldavska A, Welo T (2019) A holistic approach to corporate sustainability assessment: incorporating sustainable development goals into sustainable manufacturing performance evaluation. J Manuf Syst 50:53-68

86. Physicsweb. http://www.Miit.Gov.Cn/n1146295/n1652858/ n1652930/n3757016/c6429243/content.Html. Accessed 14 Aug 2018

87. Stock T, Seliger G (2016) Opportunities of sustainable manufacturing in Industry 4.0. Procedia CIRP 40:536-541

88. Garetti M, Taisch M (2012) Sustainable manufacturing: trends and research challenges. Prod Plan Control 23(2/3):83-104

89. He B, Zhou GF, Hou SC et al (2016) An approach to computational co-evolutionary product design. Int $\mathrm{J}$ Adv Manuf Technol 90(1/4):249-265

90. Kang HS, Lee JY, Choi S et al (2016) Smart manufacturing: past research, present findings, and future directions. Int J Precis Eng Manuf Green Technol 3(1):111-128 
91. Walshe K, McKee M, McCarthy M et al (2013) Health systems and policy research in Europe: Horizon 2020. Lancet 382(9893):668-669

92. Hemphill TA (2014) Policy debate: the US advanced manufacturing initiative: will it be implemented as an innovation-or industrial—policy? Innovation 16(1):67-70

93. Lewis P, Bell K (2019) Understanding the UK's productivity problems: new technological solutions or a case for the renewal of old institutions? Employ Relat Int J 41(2):296-312

94. Radanliev P, De Roure D, Nurse JR et al (2019) New developments in cyber physical systems, the internet of things and the digital economy-discussion on future developments in the industrial internet of things and Industry 4.0. Preprints 2019, 2019030094

95. Yeung G (2019) 'Made in China 2025': the development of a new energy vehicle industry in China. Area Dev Policy 4(1):39-59

96. Zhou GH, Zhang C, Li Z et al (2019) Knowledge-driven digital twin manufacturing cell towards intelligent manufacturing. Int $\mathrm{J}$ Prod Res 58:1034-1051

97. Lohtander M, Ahonen N, Lanz M et al (2018) Micro manufacturing unit and the corresponding 3D-model for the digital twin. Procedia Manuf 25:55-61

98. Zhang YZ, Mu LM, Shen GX et al (2019) Fault diagnosis strategy of CNC machine tools based on cascading failure. J Intell Manuf 30(5):2193-2202

99. Villalonga A, Beruvides G, Castaño F et al (2018) Conditionbased monitoring architecture for $\mathrm{CNC}$ machine tools based on global knowledge. IFAC-PapersOnLine 51(11):200-204

100. Yang HT, Li L, Zhang SD et al (2019) Critical point determination method of thermal-force coupling deformation of CNC machine tool bed. In: Tenth international symposium on precision engineering measurements and instrumentation, pp 1105325

101. Wei XY, Miao EM, Liu H et al (2019) Two-dimensional thermal error compensation modeling for worktable of $\mathrm{CNC}$ machine tools. Int J Adv Manuf Technol 101(1/4):501-509

102. Jiang ZP, Gao D, Lu Y et al (2019) Electrical energy consumption of CNC machine tools based on empirical modeling. Int J Adv Manuf Technol 100(9/12):2255-2267

103. Krimpenis AA, Fountas NA (2016) Balancing multiple criteria in formulation of weighted, single-objective genetic algorithm optimization for CNC machining problems. Adv Manuf 4(2):178-188

104. Xu X (2017) Machine tool 4.0 for the new era of manufacturing. Int J Adv Manuf Technol 92(5/8):1893-1900

105. Jeon JW, Ha YY (2000) A generalized approach for the acceleration and deceleration of industrial robots and CNC machine tools. IEEE Trans Ind Electron 47(1):133-139

106. Kim DI, Kim S (1996) An iterative learning control method with application for CNC machine tools. IEEE Trans Ind Appl 32(1):66-72

107. Keller A, Kamath A, Perera U (1982) Reliability analysis of CNC machine tools. Reliab Eng 3(6):449-473

108. Yamato S, Yamada Y, Nakanishi K et al (2018) Integrated inprocess chatter monitoring and automatic suppression with adaptive pitch control in parallel turning. Adv Manuf 6(3):291-300

109. He B, Wang J, Huang S et al (2015) Low-carbon product design for product life cycle. J Eng Des 26(10-12):321-339

110. Li YJ, Wang GC, Cui HY et al (2019) Dynamic characteristics and optimization research on PVDF piezoelectric film force sensor for steel ball cold heading machine. ISA Trans 94:265-275

111. He B, Xue HJ, Liu LL et al (2019) Rigid-flexible coupling virtual prototyping-based approach to the failure mode, effects, and criticality analysis. Int J Adv Manuf Technol 100(5/ 8):1695-1717

112. Li ZM (2016) The knowledge expression for the low carbon economy of cold heading machine. J Low Carbon Econ 05(02):20-25

113. Zhang SL, Wang S, Jing FS et al (2019) A sensorless hand guiding scheme based on model identification and control for industrial robot. IEEE Trans Ind Inf 15:5204-5213

114. Pérez L, Diez E, Usamentiaga R et al (2019) Industrial robot control and operator training using virtual reality interfaces. Comput Ind 109:114-120

115. Wu JH, Han X, Tao YR (2019) Kinematic response of industrial robot with uncertain-but-bounded parameters using interval analysis method. J Mech Sci Technol 33(1):333-340

116. Chen Z, Zhou W (2017) Path planning for a space-based manipulator system based on quantum genetic algorithm. J Robot. 3207950

117. Guo S, Fang TT, Song T et al (2018) Tracking and localization for omni-directional mobile industrial robot using reflectors. Adv Manuf 6(1):118-125

118. Slavkovic N, Zivanovic S, Milutinovic D (2019) An indirect method of industrial robot programming for machining tasks based on STEP-NC. Int J Comput Integr Manuf 32(1):43-57

119. Lyu H, Liu Y, Guo JY et al (2019) Tool-path generation for industrial robotic surface-based application. Adv Manuf 7(1):64-72

120. Berg J, Lottermoser A, Richter C et al (2019) Human-robotinteraction for mobile industrial robot teams. Procedia CIRP 79:614-619

121. Norrlof M (2002) An adaptive iterative learning control algorithm with experiments on an industrial robot. IEEE Trans Rob Autom 18(2):245-251

122. Gao Z, Zeng L, He B et al (2018) Type synthesis of non-holonomic spherical constraint underactuated parallel robotics. Acta Astronaut 152:509-520

123. He B, Wang S, Liu Y (2019) Underactuated robotics: a review. Int J Adv Robot Syst 16(4):1-29

124. He B, Zhang P, Liu W et al (2017) Dynamics analysis and numerical simulation of a novel underactuated robot wrist. Proc Inst Mech Eng J Eng Manuf 231(12):2145-2158

125. Fúnez Guerra C, Reyes-Bozo L, Vyhmeister E et al (2019) Viability analysis of underground mining machinery using green hydrogen as a fuel. Int J Hydrogen Energy 45:5112-5121

126. Islam MS, Peter N, Wiens T (2019) Simulation and experiment of vibrational or acoustic communication in mining and oil-gas drill strings. Trans Can Soc Mech Eng 43:454-462

127. Andreev V, Voronkova L, Lybianoi D (2019) Innovative technology of manufacturing of reusable metallurgical equipment with increased operational resistance from the blast furnace cast iron of the first melting. J Mater Sci Res Rev 2:1-8

128. Indri M, Lachello L, Lazzero I et al (2019) Smart sensors applications for a new paradigm of a production line. Sensors 19(3):650. https://doi.org/10.3390/s19030650

129. Dong X, Ma R (2019) Optimization of the LPCVD equipment intergraded production system of the solar cell production line. AIP Conf Proc 2122(1):1-5

130. Wang J, Li D (2019) Task scheduling based on a hybrid heuristic algorithm for smart production line with fog computing. Sensors 19(5):1-18

131. Hwang I, Jang YJ, Choi H (2018) Overhead shuttle design for a flat panel display production line considering the contactless power supply capacity. Comput Ind Eng 126:232-242

132. Gao Y, Lyu H, Hou Y et al (2019) Real-time modeling and simulation method of digital twin production line. In: 2019 IEEE 8th joint international information technology and artificial intelligence conference (ITAIC), pp 1639-1642 
133. He B, Wang J, Deng ZQ (2015) Cost-constrained low-carbon product design. Int J Adv Manuf Technol 79(9/12):1821-1828

134. Andiappan V, Benjamin MFD, Tan RR et al (2019) An integrated framework to address criticality in biomass tri-generation systems via redundancy allocation. Process Integr Optim Sustain 3(1):65-73

135. Guan D, Feng S, Zhang L et al (2019) Mesoscale simulation for heavy petroleum system using structural unit and dissipative particle dynamics (SU-DPD) frameworks. Energy Fuel 33(2):1049-1060

136. Lemu HG (2014) Current status and challenges of using geometric tolerance information in intelligent manufacturing systems. Adv Manuf 2(1):13-21

137. Sun J, Xi J, Chen X et al (2011) A CAD/CAM system for fabrication of facial prostheses. Rapid Prototyp J 17(4):253-261

138. Lv YQ, Lin DP (2017) Design an intelligent real-time operation planning system in distributed manufacturing network. Ind Manag Data Syst 117(4):742-753

139. Gu X, Jin XN, Ni J et al (2015) Manufacturing system design for resilience. Procedia CIRP 36:135-140

140. Maturana F, Shen W, Norrie DH (1999) Metamorph: an adaptive agent-based architecture for intelligent manufacturing. Int $\mathrm{J}$ Prod Res 37(10):2159-2173

141. He B, Hou S, Song W (2015) Integrating engineering design and analysis using a parameter constraint graph approach. Simulation 91(7):625-647

142. He B, Hua Y (2016) Synthesis of mechanisms integrated with motion and force transformation. Int $\mathrm{J}$ Precis Eng Manuf 17(12):1643-1649

143. He B, Huang S (2016) Functional synthesis of mechanisms under cost consideration. Proc Inst Mech Eng J Eng Manuf 230(1):91-99

144. He B, Song W, Wang Y (2015) Computational conceptual design using space matrix. J Comput Inf Sci Eng 15(1):1-7

145. He B, Song W, Wang YG (2013) A feature-based approach towards an integrated product model in intelligent design. Int $\mathbf{J}$ Adv Manuf Technol 69(1/4):15-30

146. He B, Zhang P, Wang J (2014) Automated synthesis of mechanisms with consideration of mechanical efficiency. J Eng Des 25(4/6):213-237

147. He B, Zhang P, Zhu N et al (2016) Skeleton model-based approach to integrated engineering design and analysis. Int $\mathrm{J}$ Adv Manuf Technol 85(5):1105-1115

148. He B, Ostrosi E, Pfaender F et al (2014) Intelligent engineering design of complex city: a co-evolution model. In: Cha J, Chou SY, Stjepandic J et al (eds) Moving integrated product development to service clouds in the global economy. IOS Press, Amsterdam, pp 434-443

149. He B, Luo T, Huang S (2019) Product sustainability assessment for product life cycle. J Clean Prod 206:238-250

150. He B, Deng ZQ, Huang S et al (2015) Application of unascertained number for the integration of carbon footprint in conceptual design. Proc Inst Mech Eng $J$ Eng Manuf 229(11):2088-2092

151. Yu QY, He B (2020) Automated sustainable low-carbon design of offshore platform for product life cycle. In: Tan J (ed) Advances in mechanical design. Springer, Berlin, pp 1-17

152. He B, Huang S, Wang J (2015) Product low-carbon design using dynamic programming algorithm. Int J Precis Eng Manuf Green Technol 2(1):37-42

153. He B, Tang W, Wang J (2015) Product model integrated with carbon footprint for low-carbon design. Int J Precis Eng Manuf 16(11):2383-2388

154. He B, Feng P (2012) Guiding conceptual design through functional space exploration. Int J Adv Manuf Technol 66(9/ 12):1999-2011
155. Gregor M, Hercko J, Fusko M et al (2019) Zilina intelligent manufacturing system: best practice of cooperation between university and research center. In: Caganova D, Balog M, Knapcikova L et al (eds) Smart technology trends in industrial and business management. Springer, Berlin, pp 183-198

156. He B, Li FF, Cao XY et al (2020) Product sustainable design: a review from the environmental, economic, and social aspects. ASME J Comput Inf Sci Eng 20:040801

157. He B, Wang YG, Song W et al (2014) Design resource management for virtual prototyping in product collaborative design. Proc Inst Mech Eng J Eng Manuf 229(12):2284-2300

158. Simeone A, Caggiano A, Boun L et al (2019) Intelligent cloud manufacturing platform for efficient resource sharing in smart manufacturing networks. Procedia CIRP 79:233-238

159. Wang S, Liang YC, Li WD et al (2018) Big data enabled intelligent immune system for energy efficient manufacturing management. J Clean Prod 195:507-520

160. Stadnicka D, Litwin P, Antonelli D (2019) Human factor in intelligent manufacturing systems-knowledge acquisition and motivation. Procedia CIRP 79:718-723

161. He B, Tang W, Wang J et al (2015) Low-carbon conceptual design based on product life cycle assessment. Int J Adv Manuf Technol 81(5/8):863-874

162. Tao F, Cheng Y, Xu LD et al (2014) CCIOT-CMFG: cloud computing and internet of things-based cloud manufacturing service system. IEEE Trans Ind Inf 10(2):1435-1442

163. Lin YC, Hung MH, Huang HC et al (2017) Development of advanced manufacturing cloud of things (AMCOT) - a smart manufacturing platform. IEEE Rob Autom Lett 2(3):1809-1816

164. He B, Zhang P, Liu L (2014) Simultaneous functional synthesis of mechanisms with mechanical efficiency and cost. Int J Adv Manuf Technol 75(5/8):659-665

165. Zhang YF, Qian C, Lyu JX et al (2017) Agent and cyberphysical system based self-organizing and self-adaptive intelligent shopfloor. IEEE Trans Ind Inf 13(2):737-747

166. Lee CKM, Zhang SZ, Ng KKH (2017) Development of an industrial internet of things suite for smart factory towards reindustrialization. Adv Manuf 5(4):335-343

167. He B, Niu YC, Hou SC et al (2018) Sustainable design from functional domain to physical domain. J Clean Prod 197:1296-1306

168. Helo P, Suorsa M, Hao Y et al (2014) Toward a cloud-based manufacturing execution system for distributed manufacturing. Comput Ind 65(4):646-656

169. Guo QL, Zhang M (2009) A novel approach for multi-agentbased intelligent manufacturing system. Inf Sci 179(18):3079-3090

170. Ji X, He G, Xu JJ et al (2016) Study on the mode of intelligent chemical industry based on cyber-physical system and its implementation. Adv Eng Software 99:18-26

171. Tao F, Zuo Y, Xu LD et al (2014) IoT-based intelligent perception and access of manufacturing resource toward cloud manufacturing. IEEE Trans Ind Inf 10(2):1547-1557

172. Jain P, Poon J, Singh JP et al (2019) A digital twin approach for fault diagnosis in distributed photovoltaic system. IEEE Trans Power Electron 35:940-956

173. Liu MZ, Ma J, Lin L et al (2014) Intelligent assembly system for mechanical products and key technology based on internet of things. J Intell Manuf 28(2):271-299

174. Tang H, Li D, Wang SY et al (2018) Casoa: an architecture for agent-based manufacturing system in the context of Industry 4.0. IEEE Access 6:12746-12754

175. Chaplin J, Bakker O, de Silva L et al (2015) Evolvable assembly systems: a distributed architecture for intelligent manufacturing. IFAC-PapersOnLine 48(3):2065-2070 
176. Wang KS (2013) Towards zero-defect manufacturing (ZDM)a data mining approach. Adv Manuf 1(1):62-74

177. Liu C, Jiang PY (2016) A cyber-physical system architecture in shop floor for intelligent manufacturing. Procedia CIRP 56:372-377

178. Wan JF, Yi ML, Li D et al (2016) Mobile services for customization manufacturing systems: an example of Industry 4.0. IEEE Access 4:8977-8986

179. Zhao QJ, Cao P, Tu DW (2014) Toward intelligent manufacturing: label characters marking and recognition method for steel products with machine vision. Adv Manuf 2(1):3-12

180. Liu CW, Chien CF (2013) An intelligent system for wafer bin map defect diagnosis: an empirical study for semiconductor manufacturing. Eng Appl Artif Intell 26(5/6):1479-1486

181. Strandhagen JW, Alfnes E, Strandhagen JO et al (2017) The fit of Industry 4.0 applications in manufacturing logistics: a multiple case study. Adv Manuf 5(4):344-358

182. Chen RY (2017) An intelligent value stream-based approach to collaboration of food traceability cyber physical system by fog computing. Food Control 71:124-136

183. Maoudj A, Bouzouia B, Hentout A et al (2017) Distributed multi-agent scheduling and control system for robotic flexible assembly cells. J Intell Manuf 30(4):1629-1644

184. Barenji AV, Barenji RV, Hashemipour M (2016) Flexible testing platform for employment of RFID-enabled multi-agent system on flexible assembly line. Adv Eng Softw 91:1-11

185. Wang KS (2014) Intelligent and integrated RFID (II-RFID) system for improving traceability in manufacturing. Adv Manuf 2(2):106-120

186. Zhong RY, Dai QY, Qu T et al (2013) RFID-enabled real-time manufacturing execution system for mass-customization production. Robot Comput Integr Manuf 29(2):283-292

187. Leng JW, Jiang PY (2017) Dynamic scheduling in RFID-driven discrete manufacturing system by using multi-layer network metrics as heuristic information. J Intell Manuf 30(3):979-994

188. Guo ZX, Wong WK, Guo CX (2013) A cloud-based intelligent decision-making system for order tracking and allocation in apparel manufacturing. Int J Prod Res 52(4):1100-1115

189. Qiu C (2018) Implementation of vehicle mobile sales cloud management system based on intelligent community. In: 2018 14th international conference on computational intelligence and security (CIS), pp 341-344

190. Zhang XY, Ming XG, Liu ZW et al (2019) An overall framework and subsystems for smart manufacturing integrated system (SMIS) from multi-layers based on multi-perspectives. Int J Adv Manuf Technol 103:703-722

191. He B, Liu YJ, Zeng LB et al (2020) Product carbon footprint across sustainable supply chain. J Clean Prod 241:118320

192. Sun HT, Peng C, Zhou P et al (2017) A brief overview on secure control of networked systems. Adv Manuf 5(3):243-250

193. McFarlane D, Sarma S, Chirn JL et al (2003) Auto ID systems and intelligent manufacturing control. Eng Appl Artif Intell 16(4):365-376

194. Cui FZ, Xu ZZ, Wang XK et al (2018) A dual-system cooperative co-evolutionary algorithm for satellite equipment layout optimization. Proc Inst Mech Eng G J Aerosp Eng 232(13):2432-2457

195. Malik AA, Bilberg A (2018) Phygital workspace as a digital twin for design \& planning of smart factories, pp 1-2

196. Yin Y, Sun L, Guo C (2008) A policy of conflict negotiation based on fuzzy matter element particle swarm optimization in distributed collaborative creative design. Comput Aided Des 40(10/11):1009-1014

197. Wang Y, Ma HS, Yang JH et al (2017) Industry 4.0: a way from mass customization to mass personalization production. Adv Manuf 5(4):311-320
198. Rødseth H, Schjølberg P, Marhaug A (2017) Deep digital maintenance. Adv Manuf 5(4):299-310

199. Gamboa Quintanilla F, Cardin O, L'Anton A et al (2016) A modeling framework for manufacturing services in service-oriented holonic manufacturing systems. Eng Appl Artif Intell $55: 26-36$

200. He B, Zhu XR, Zhang D (2020) Boundary encryption-based Monte Carlo learning method for workspace modeling. ASME J Comp Inf Sci Eng. 20:034502. https://doi.org/10.1115/1. 4046816

201. Li F, Zhang L, Liu YK et al (2017) A clustering network-based approach to service composition in cloud manufacturing. Int $\mathrm{J}$ Comput Integr Manuf 30(12):1331-1342

202. Lu YQ, Xu X (2017) A semantic web-based framework for service composition in a cloud manufacturing environment. J Manuf Syst 42:69-81

203. Zhang S, Xu YB, Zhang WY et al (2017) A new fuzzy QOSaware manufacture service composition method using extended flower pollination algorithm. J Intell Manuf 30(5):2069-2083

204. Zhou JJ, Yao XF (2016) A hybrid artificial bee colony algorithm for optimal selection of QOS-based cloud manufacturing service composition. Int J Adv Manuf Technol 88(9/12):3371-3387

205. Yao F, Yao YP, Xing LN et al (2019) An intelligent scheduling algorithm for complex manufacturing system simulation with frequent synchronizations in a cloud environment. Memet Comput 11:357-370

206. Ruiz N, Giret A, Botti V et al (2014) An intelligent simulation environment for manufacturing systems. Comput Ind Eng $76: 148-168$

207. Zheng Y, Yang S, Cheng HC (2018) An application framework of digital twin and its case study. J Ambient Intell Hum Comput 10(3):1141-1153

208. Zhang C, Zhou G (2019) A view-based 3D CAD model reuse framework enabling product lifecycle reuse. Adv Eng Softw 127:82-89

209. He B, Tang W, Huang S et al (2015) Towards low-carbon product architecture using structural optimization for lightweight. Int J Adv Manuf Technol 83(5/8):1419-1429

210. Bodrow W (2014) The dynamic of professional knowledge utilized in software applications for process controlling. Adv Manuf 2(2): 173-178

211. Giret A, Trentesaux D, Salido MA et al (2017) A holonic multiagent methodology to design sustainable intelligent manufacturing control systems. J Clean Prod 167:1370-1386

212. Zhang C, Zhou G, Lu Q et al (2017) Graph-based knowledge reuse for supporting knowledge-driven decision-making in new product development. Int J Prod Res 55(23):7187-7203

213. Chai JF, Hu XM, Qu HW et al (2018) Production line 3D visualization monitoring system design based on OpenGL. Adv Manuf 6(1):126-135

214. Huang PB, Zhang HJ, Lin YC (2017) Development of a grey online modeling surface roughness monitoring system in end milling operations. J Intell Manuf 30(4):1923-1936

215. Li Z, Wang Y, Wang KS (2017) Intelligent predictive maintenance for fault diagnosis and prognosis in machine centers: Industry 4.0 scenario. Adv Manuf 5(4):377-387

216. Kim J, Hwangbo H (2019) Real-time early warning system for sustainable and intelligent plastic film manufacturing. Sustainability 11(5):1490-1503

217. Guo ZX, Ngai EWT, Yang C et al (2015) An RFID-based intelligent decision support system architecture for production monitoring and scheduling in a distributed manufacturing environment. Int J Prod Econ 159:16-28

218. Tan DP, Zhang LB, Ai QL (2016) An embedded self-adapting network service framework for networked manufacturing system. J Intell Manuf 30(2):539-556 
219. Arica E, Powell DJ (2014) A framework for ICT-enabled realtime production planning and control. Adv Manuf 2(2):158-164

220. Su Y, Ding X, Zheng H et al (2009) A new method of remote control for embedded terminal based on browser/server/terminal model. In: 2009 Pacific-Asia conference on circuits, communications and systems, pp 151-154

221. Theorin A, Bengtsson K, Provost J et al (2016) An event-driven manufacturing information system architecture for Industry 4.0. Int J Prod Res 55(5):1297-1311

222. Xiao X, Wang SF, Zhang LJ et al (2018) Complexity analysis of manufacturing service ecosystem: a mapping-based computational experiment approach. Int J Prod Res 57(2):357-378

223. Baxter D, Roy R, Doultsinou A et al (2009) A knowledge management framework to support product-service systems design. Int J Comput Integr Manuf 22(12):1073-1088

224. Matsas M, Pintzos G, Kapnia A et al (2017) An integrated collaborative platform for managing product-service across their life cycle. Procedia CIRP 59:220-226

225. Balta EC, Lin Y, Barton K et al (2018) Production as a service: a digital manufacturing framework for optimizing utilization. IEEE Trans Autom Sci Eng 15(4):1483-1493

226. Cheng Y, Bi LN, Tao F et al (2018) Hypernetwork-based manufacturing service scheduling for distributed and collaborative manufacturing operations towards smart manufacturing. J Intell Manuf. https://doi.org/10.1007/s10845-018-1417-8

227. Ren M, Ren L, Jain H (2018) Manufacturing service composition model based on synergy effect: a social network analysis approach. Appl Soft Comput 70:288-300

228. Siderska J, Jadaan KS (2018) Cloud manufacturing: a serviceoriented manufacturing paradigm. A review paper. Eng Manag Prod Serv 10(1):22-31

229. He B, Feng PE (2012) Research on collaborative conceptual design based on distributed knowledge resource. Int $\mathrm{J}$ Adv Manuf Technol 66(5/8):645-662

230. Yang YF, Yang B, Wang SL et al (2019) A dynamic ant-colony genetic algorithm for cloud service composition optimization. Int J Adv Manuf Technol 102(1/4):355-368

231. Zhou JJ, Yao XF (2017) A hybrid approach combining modified artificial bee colony and cuckoo search algorithms for multiobjective cloud manufacturing service composition. Int J Prod Res 55(16):4765-4784

232. Zhang CL, Sheng BY, Yin XY et al (2017) Research and development of off-line services for the $3 \mathrm{D}$ automatic printing machine based on cloud manufacturing. J Ambient Intell Hum Comput 10(3):1109-1128

233. Huang BQ, Li CH, Tao F (2013) A chaos control optimal algorithm for QOS-based service composition selection in cloud manufacturing system. Enterp Inf Syst 8(4):445-463

234. Guo L, Wang SL, Kang L et al (2015) Agent-based manufacturing service discovery method for cloud manufacturing. Int J Adv Manuf Technol 81(9/12):2167-2181

235. Song TX, Liu HM, Wei CM et al (2014) Common engines of cloud manufacturing service platform for SMES. Int J Adv Manuf Technol 73(1/4):557-569

236. DeSmit Z, Elhabashy AE, Wells LJ et al (2017) An approach to cyber-physical vulnerability assessment for intelligent manufacturing systems. J Manuf Syst 43:339-351

237. Wang KS, Sharma VS, Zhang ZY (2014) SCADA data based condition monitoring of wind turbines. Adv Manuf 2(1):61-69

238. Feng Y, Huang BQ (2018) Cloud manufacturing service QOS prediction based on neighbourhood enhanced matrix factorization. J Intell Manuf. https://doi.org/10.1007/s10845-018-1409-8

239. Lartigau J, Xu XF, Nie LS et al (2015) Cloud manufacturing service composition based on QOS with geo-perspective transportation using an improved artificial bee colony optimisation algorithm. Int J Prod Res 53(14):4380-4404

240. Wang KS, Li Z, Braaten $J$ et al (2015) Interpretation and compensation of backlash error data in machine centers for intelligent predictive maintenance using ANNs. Adv Manuf 3(2):97-104

241. Liu ZW, Ming XG (2019) A framework with revised roughDEMATEL to capture and evaluate requirements for smart industrial product-service system of systems. Int J Prod Res 57:7104-7122

242. Liu Q, Liu ZH, Xu WJ et al (2019) Human-robot collaboration in disassembly for sustainable manufacturing. Int $\mathrm{J}$ Prod Res 57:4027-4044

243. Dyllick T, Rost Z (2017) Towards true product sustainability. J Clean Prod 162:346-360

244. He B, Gu ZC (2016) Sustainable design synthesis for product environmental footprints. Des Stud 45:159-186

245. He B, Xiao JL, Deng ZQ (2018) Product design evaluation for product environmental footprint. J Clean Prod 172:3066-3080

246. Manfredi S, Allacker K, Pelletier N et al (2012) Product environmental footprint (PEF) guide. European Commission

247. He B, Shao Y, Wang S et al (2019) Product environmental footprints assessment for product life cycle. J Clean Prod 233:446-460

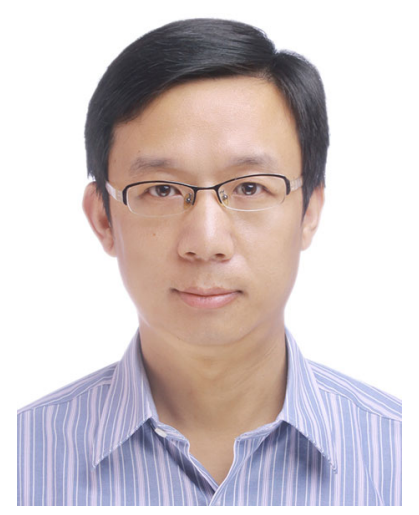

Bin He received his degrees (from Bachelor to Ph.D Degree) from Zhejiang University. Dr. $\mathrm{He}$ is a Full Professor and Deputy Director of Shanghai Key Laboratory of Intelligent Manufacturing and Robotics, Director of Robotics and Intelligent Design Institute, School of Mechatronic Engineering and Automation, Shanghai University. Dr. He is Associate Editor of ASME Journal of Computing and Information Science in Engineering, Editor-in-Chief of International Journal of Advanced Robotic Systems. Dr. He has interests in sustainable intelligent design and intelligent manufacturing, and robotics.

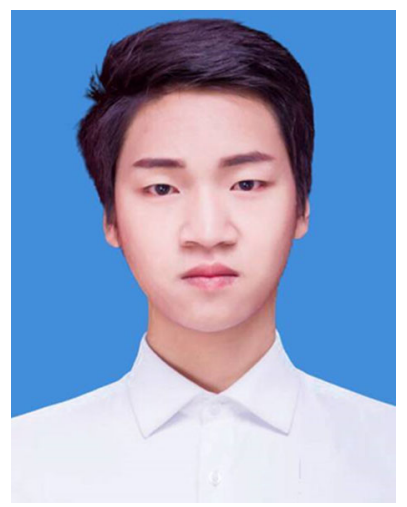

Kai-Jian Bai received a BS degree in Mechanical Engineering from Shanghai University, P.R.C., in 2018. He is now studying for a master's degree in the School of Mechatronic Engineering and Automation, Shanghai University. He has interests in intelligent manufacturing systems. 